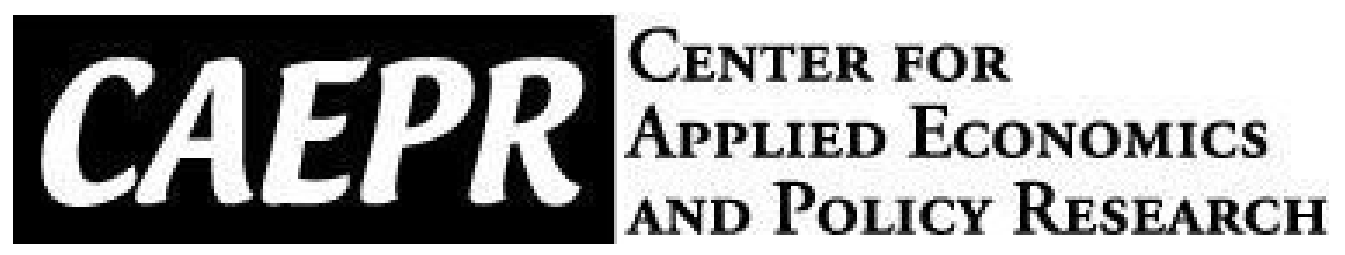

\author{
CAEPR \\ Working Paper \\ \#2017-016
}

U.S. Monetary-Fiscal Regime Changes in the Presence of

Endogenous Feedback in Policy Rules

Yoosoon Chang

Indiana University

Department of

Economics

Boreum Kwak

Martin-Luther University Halle-Wittenberg and Halle Institute for Economic Research

October 13, 2017

This paper can be downloaded without charge from the Social Science Research Network electronic library at https://papers.ssrn.com/abstract_id=3080558

The Center for Applied Economics and Policy Research resides in the Department of Economics at Indiana University Bloomington. CAEPR can be found on the Internet at: http://www.indiana.edu/ caepr. CAEPR can be reached via email at caepr@indiana.edu or via phone at 812-855-4050.

(C)2017 by Yoosoon Chang and Boreum Kwak. All rights reserved. Short sections of text, not to exceed two paragraphs, may be quoted without explicit permission provided that full credit, including (C) notice, is given to the source. 


\title{
U.S. Monetary-Fiscal Regime Changes in the Presence of Endogenous Feedback in Policy Rules*
}

\author{
Yoosoon Chang \\ Department of Economics \\ Indiana University
}

\author{
Boreum Kwak \\ Martin-Luther University Halle-Wittenberg \\ and Halle Institute for Economic Research
}

October 13, 2017

\begin{abstract}
We investigate U.S. monetary and fiscal policy regime interactions in a model, where regimes are determined by latent autoregressive policy factors with endogenous feedback. Policy regimes interact strongly: shocks that switch one policy from active to passive tend to induce the other policy to switch from passive to active, consistently with existence of a unique equilibrium, though both policies are active and government debt grows rapidly in some periods. We observe relatively strong interactions between monetary and fiscal policy regimes after the recent financial crisis. Finally, latent policy regime factors exhibit patterns of correlation with macroeconomic time series, suggesting that policy regime change is endogenous.
\end{abstract}

JEL Classification: C13, C32, C38, E52, E58, E63

Key words and phrases: monetary and fiscal policy interactions, endogenous regime switching, adaptive LASSO, time-varying coefficient VAR, factor augmented VAR.

\footnotetext{
${ }^{*}$ We are very grateful to Eric M. Leeper for many insightful comments which significantly improved earlier versions of the paper, and also to Joon Y. Park, Yongok Choi, and Jihyun Kim for numerous discussions and invaluable suggestions. We thank the participants at 2015 Midwest Econometrics Group Meetings, 2016 St. Louis FED Econometrics Workshop, 2016 International Association of Applied Econometrics, 2016 Asian Meeting of Econometric Society, 2016 CFE-CMStatistics, 2017 SNDE conference and the seminar participants at New York University, NY FED, Columbia University, University of Cincinnati, Texas A\&M University, Sungkyunkwan University, Tsinghua University, Indiana University, Seoul National University, Bank of Korea, and Banque de France for their helpful comments and feedback.
} 


\section{Introduction}

The recent financial crisis and great recession have generated growing interest in the interaction of monetary and fiscal policies. Theoretical analyses of policy interaction focus on how monetary and fiscal regimes can jointly accomplish the tasks of price level determination and debt stabilization; see, e.g., Sargent and Wallace (1981), Wallace (1981), Aiyagari and Gertler (1985), Sims (1988), and Leeper (1991). The conventional policy regime has central banks stabilize inflation by systematically raising nominal interest rates more than one-for-one with inflation while the fiscal authority adjusts taxes or government spending to assure fiscal solvency. An alternative regime reverses the policy roles: fiscal policy determines the price level, and monetary policy stabilizes debt. By making primary surpluses insensitive to debt, the price level adjusts to equate the real value of outstanding debt to the expected discounted present value of primary surpluses. Monetary policy passively permits the necessary change in the current and future price levels to occur by responding weakly to current inflation. Leeper (1991) labels the conventional regime M (active monetary/passive fiscal) and the alternative regime $\mathrm{F}$ (passive monetary/active fiscal). Both of these regimes are consistent with the existence of a determinate bounded rational expectations equilibrium.

Although economic theory emphasizes monetary and fiscal regimes, most empirical studies focus on dynamic patterns of correlation among policy variables. King and Plosser (1985) study the relationship between fiscal deficits and inflation using U.S. data and find no empirical evidence of a relationship. Melitz $(1997,2000)$ investigates the interaction between monetary and fiscal policies over the business cycle using a data set for 19 OECD countries and shows that the two policies tend to move in opposite directions. Kliem et al. (2016) estimate the low-frequency relationship between primary deficits over debt and inflation in a time-varying VAR model for U.S. data. They find that the relationship between inflation and primary deficits over debt is mostly positive before 1980 and insignificantly different from zero after 1980. See also von Jagen et al. (2001) and Muscatelli et al. (2002) for some related work.

However, correlations among policy variables can tell us nothing about interactions between policy regimes. Some recent work explores dynamic interactions between monetary and fiscal regimes. Favero and Monacelli (2005) consider monetary and fiscal regime switching and find that regime switches in monetary and fiscal policy rules do not exhibit any degree of synchronization. Davig and Leeper (2006b) consider monetary and fiscal regime switching using U.S. data. After imposing the estimated policy process on a conventional calibrated dynamic stochastic general equilibrium (DSGE) model with nominal rigidities, they provide an interpretation of post-war macro policies. Gonzalez-Astudillo (2013) considers time variation in the policy rules by specifying coefficients that are logistic functions of correlated latent factors and finds that there is a nonnegligible degree of interdependence between policies. Bianchi and Ilut (2017) estimate a model for U.S. economy with monetary/fiscal mix changes and explain why inflation dropped in the 1980s in terms of the policy change. They are, though, all based on the conventional regime switching model, which assumes that switching of monetary and fiscal regimes is entirely exogenous. Exogenous 
regime change is silent about a causal mechanism which connects changes in monetary regime to switches in fiscal regime.

This paper takes an important step toward bringing empirical work on regime change closer to theory by allowing endogenous feedback in switching of monetary and fiscal regimes in our model with simple monetary and fiscal rules. Monetary policy follows a simplified Taylor-type rule that makes the nominal interest rate depend on inflation and a monetary disturbance. Fiscal policy adjusts tax revenues in response to current government purchases, the real market value of outstanding government debt, and a fiscal disturbance. Policy regimes are determined by an autoregressive latent policy factor with endogenous feedback, and regime change is triggered whenever the latent policy regime factor crosses a threshold. Using our model, we estimate regime switching monetary and fiscal policy rules that describe purposeful policy behavior in which policy rule coefficients respond to the state of economy systematically, and examine policy regime interactions using policy regime factors that determine policy regimes explicitly in our policy rules.

Endogenous feedback in regime change arises from two aspects of the econometric structure: (1) choices of policy instruments depend on systematic responses to target variables plus a disturbance that reflects how policy choice reacts to non-target information; (2) policy parameters are functions of a latent policy factor whose dynamic evolution depends on both past policy disturbances and an exogenous shock. For example, if at time $t$ policy sets the instrument above the level that the systematic response to the targets implies, this positive disturbance predicts future changes in the latent factor and, therefore, in the policy regime. Two economic effects come from such a disturbance. First, there is the direct effect of a higher realization of the policy instrument. Because the disturbance carries with it information about future realizations of the systematic reactions of policy to targets, a second effect arises from changes in private agents' expectations of policy regime.

Our regime switching setup has a natural interpretation in terms of actual policy behavior. Rarely do policy makers choose to shift discretely to a new regime. Instead, policy choices typically evolve from one regime to another, an evolution captured by the dynamics of the latent factor. On the other hand, the econometric method is flexible enough to also handle sudden changes in regime that are triggered by unusually large realizations of the policy disturbance or the exogenous shock to the latent factor. We estimate models for monetary and fiscal policies separately ${ }^{1}$ by the maximum likelihood method, using a modified version of the filter developed by Chang et al. (2017) to allow for switching in the policy coefficients. We find two interpretable policy regimes for monetary and fiscal policy rules (active/passive), between which policy rules fluctuate. Estimates undercover strong evidence of endogenous feedback, rejecting the null of no endogenous feedback at $1 \%$ significance level.

The most interesting and novel implications of this work come from studying dynamic interactions between the two policy regime factors and among regimes and macroeconomic variables.

\footnotetext{
${ }^{1}$ Treating policies as separate should be understood as illustrative to demonstrate clearly the value-added of the technique before tackling a more plausible, but significantly more complex, system of equations.
} 
This analysis sheds light on how monetary policy's choice of its rule may influence fiscal policy's choice of its rule (and vice versa). Every central bank takes the stance of fiscal policy into account in its policy choices. ${ }^{2}$

We analyze the dynamic interactions of the policy regime factors in a time-varying coefficient VAR (TVC-VAR) model. Policy interactions have changed historically:

- After a shock to the monetary policy factor that makes the regime passive, the regime tends to remain passive, suggesting stability in policy behavior. That stability is strongest over a sample that includes the 1980s, a time when most observers believe U.S. monetary policy was sharply focused on inflation control. Except during the 1950s, that monetary regime shock drives fiscal policy toward an active regime to produce a passive monetary/active fiscal combination that theory suggests delivers a determinate, well-behaved equilibrium.

- A negative shock to the fiscal policy factor that makes the regime active is followed by persistently active fiscal behavior. Monetary policy's response to the fiscal disturbance, however, varies over the sample. In the 1950s, monetary policy tends to become active. The doubly active policy mix, according to theory, stabilizes neither inflation nor debt. Sample periods that include data from the 1990s or more recently find monetary policy reacting by becoming passive to put the economy in a stabilizing policy regime.

- During the 1990s and 2000s, policy regimes were mostly active monetary/passive fiscal. But following a negative shock to the fiscal policy factor that makes the regime active, monetary policy tends to become passive even during periods when the prevailing mix is active monetary and passive fiscal. This supports work that argues that the fiscal theory is operating whenever economic agents believe it is possible for fiscal policy to become active, even when the rules in place at a given moment would suggest that Ricardian equivalence should hold if regime were fixed (Davig et al. (2004) and Davig and Leeper (2006b)).

We also investigate various aspects of interactions between policy regimes and macroeconomic variables. First, we find which macro variables mainly explain the regime switching in the policy rules and how policy regime factors are related to the state of the macroeconomy via adaptive least absolute shrinkage and selection operator (LASSO). The fiscal variables, tax to GDP ratio and net interest payment to government spending ratio, are selected as some of the most important variables in explaining the monetary regime factor, and the monetary policy factor has the largest estimated coefficient for the fiscal regime factor. This result can be regarded as an indirect evidence of policy interactions. Second, we use a small-scale structural VAR model to show how non-policy regime factors induce policy regime interactions. Shocks to non-policy regime factors, especially those that embody real activity, generate movements in policy regime factors that are theoretically plausible.

\footnotetext{
${ }^{2}$ King (1995) famously wrote: "Central banks are often accused of being obsessed with inflation. This is untrue. If they are obsessed with anything, it is with fiscal policy." Analogously, fiscal authorities routinely project interest rates when reaching debt-management decisions.
} 
Finally, to estimate how key macroeconomic variables affect the policy regime interactions, we conduct counterfactual analysis using the factor-augmented VAR (FAVAR) that Bernanke et al. (2005) introduced. Changes in policy regimes induce dynamic impacts on the key macro variables that accord well with a priori expectations.

The rest of the paper is organized as follows. In Section 2, we introduce our regime switching policy rules with endogenous feedback and provide economic interpretations on our model specification. We also estimate endogenous regime switching monetary and fiscal policy rules and give explanations for the plausibility of estimates. Section 3 explains how monetary and fiscal policy rules have interacted using endogenous policy regime factors in various aspects. Section 4 links the policy regime factors to macro economy by analyzing their dynamic interactions with the key macroeconomic variables and leading macro factors. Section 5 reports robustness of our results to the presence of stochastic volatility and the zero lower bound. Section 6 concludes the paper, and the Appendix collects additional figures, results from the additional analyses and detailed data description.

\section{$2 \quad$ Policy Rules with Endogenous Feedback}

We use a regime switching model with endogenous feedback as in Chang et al. (2017). In our model, regime switching is determined by an autoregressive latent factor with endogenous feedback. We consider the policy rule equation

$$
y_{t}=x_{t}^{\prime} \beta_{s t}+u_{t}
$$

where $y_{t}$ and $x_{t}$ are, respectively, the policy instrument and the policy target variables believed to be considered by the policy makers at time $t ; \beta_{s_{t}}$ is the state-dependent policy parameter that is defined more precisely below; and $u_{t}$ signifies the policy disturbance that satisfies

$$
\mathbb{E}\left[u_{t} \mid s_{t}, x_{t}, \mathcal{G}_{t-1}\right]=0,
$$

where $\mathcal{G}_{t-1}$ is the information available at time $t-1$ to the policy makers, which will be specified more precisely later. We may view the policy disturbance $u_{t}$ as the part of the policy instrument variable $y_{t}$ that is not predicted by the policy target variables $x_{t}$. The policy disturbance $u_{t}$ represents the multitude of all other factors that affect the policy making, such as the policy shocks and other policy concerns not measured by the policy target variables $x_{t}$, and hence, it is not regarded as an exogenous shock from the perspective of the policy maker. Rather the policy disturbance represents systematic responses of the policy makers to the state of the economy, other than the aspects of the state that are already reflected in the policy target variables $x_{t}$ included as the right-hand-side variables.

The state variable $s_{t}$ determining the policy regime is specified as

$$
s_{t}=1\left\{w_{t} \geq \psi\right\}
$$


with a latent policy factor $w_{t}$ representing the internal information set used by a policy maker for her policy decision, and $\psi$ is a threshold parameter. The policy factor is assumed to evolve over time as

$$
w_{t}=\alpha w_{t-1}+v_{t}
$$

where $v_{t}$ and $u_{t-1}$ are jointly i.i.d. normal with unit variance and $\operatorname{cov}\left(u_{t-1}, v_{t}\right)=\rho$. The conditional distribution of $v_{t}$ given $u_{t-1}$ is normal with mean $\rho u_{t-1}$ and variance $1-\rho^{2}$; therefore, the presence of endogeneity dampens the variability of the policy factor shock $v_{t}$ and consequently weakens its idiosyncratic component of $v_{t}$ independent of $u_{t-1}$. We expect $\rho \neq 0$, so we have a feedback channel in the policy rule (1). A part of the policy disturbance $u_{t-1}$ incurred in the previous period will affect the change in the policy choice $\beta_{s t}$ in the current period through its endogeneity, with the shock $v_{t}$ to the current policy factor $w_{t}$ that determines the current policy regime. We therefore infer how much exogenous component is left in the policy factor from the degree of endogeneity $\rho$.

In our model with $\rho \neq 0$, allowing for an endogenous feedback, we envision that policy maker purposefully chooses policy parameter $\beta_{s_{t}}$ and subsequently policy disturbance $u_{t}=y_{t}-x_{t}^{\prime} \beta_{s_{t}}$. The current policy choice $\beta_{s_{t}}$ depends on the previous policy disturbance $u_{t-1}$ at time $t-1$ and also on an independent component realized at the current period $t$. This means, of course, that policy's current choice of $u_{t}$ influences future choices of $\beta_{s_{t}}$ to introduce an element of constrained discretion to policy choice. More explicitly, we assume that $\beta_{s_{t}}$ in the current period $t$ is updated according to the policy choice

$$
\beta_{s_{t}}=\underset{\beta}{\operatorname{argmin}} \mathbb{E}\left[\left(y_{t}-x_{t}^{\prime} \beta\right)^{2} \mid s_{t}, x_{t}, \mathcal{G}_{t-1}\right]
$$

where $\mathcal{G}_{t-1}$ includes the entire history of policy instrument $y$, policy target variables $x$, and state variable $s$ (and therefore policy disturbance $u$, too) up to time $t-1$. This means that $\beta_{s_{t}}$ minimizes the mean squared error loss incurred by policy disturbance at each time $t$ conditionally on state $s_{t}$ and target variables $x_{t}$ at time $t$, and all other information available to the policy maker at time $t-1$. Therefore, in particular, our state-dependent policy choice $\beta_{s_{t}}$ in (2) specifies (1) as a well formulated regression satisfying the usual orthogonality condition between regressor and regression error. Policy choice in (2) naturally entails policy rule in (1) above.

This is in sharp contrast with the conventional Markov switching model, which assumes $\rho=0$. Under this exogeneity assumption, there is no feedback channel in policy rule. Consequently, all past states and policy disturbances become irrelevant in setting a state-dependent policy rule. In fact, in this case, we have

$$
\beta_{s_{t}}=\underset{\beta}{\operatorname{argmin}} \mathbb{E}\left[\left(y_{t}-x_{t}^{\prime} \beta\right)^{2} \mid s_{t}, x_{t}, \mathcal{F}_{t-1}\right]
$$

where $\mathcal{F}_{t-1}$ only includes policy instrument $y$ and policy target $x$ observed at time $t-1$, excluding all other past states and policy disturbances. Under the conventional exogenous regime switching 
model, the policy choice is not affected by past states and policy disturbances. In the existing literature, a wide class of regime switching policy rules is considered and analyzed by many authors (see, e.g., Davig (2004), Davig and Leeper (2006b), Favero and Monacelli (2005), Sims and Zha (2006), Gonzalez-Astudillo (2013), and Bianchi and Ilut (2017)). The major difference between our regime switching policy rules from the existing conventional regime switching policy rules is the presence of endogenous feedback in our regime switching. ${ }^{3}$

In what follows, we specify the regime switching models with endogenous feedback for monetary and fiscal policy rules, and subsequently estimate the models using the U.S. data. Finally, we consider the plausibility of our estimates based on narrative accounts of policy behavior.

\subsection{Policy Rules with Regime Switching}

We consider a simple Taylor (1993) rule type monetary policy that makes the nominal interest rate, $i_{t}$, depend only on inflation, $\pi_{t}:^{4}$

$$
i_{t}=a_{c}\left(s_{t}^{m}\right)+a_{\pi}\left(s_{t}^{m}\right) \pi_{t}+\sigma^{m} u_{t}^{m},
$$

where $s_{t}^{m}$ represents a state process specifying a binary state of regime in monetary policy at time $t$, and $s_{t}=0$ and 1 are regimes that respond to the inflation weakly and aggressively, respectively. $a_{j}\left(s_{t}^{m}\right), j=c, \pi$, are state-dependent monetary policy parameters, and $u_{t}^{m}$ represents the monetary policy disturbance. We may let $s_{t}^{m}=1\left\{w_{t}^{m} \geq \psi_{m}\right\}$, where $w_{t}^{m}$ is a latent monetary policy factor representing internal information set used by a central bank for her policy decisions and $\psi_{m}$ is a threshold. Monetary policy makers' information set is assumed to be larger than that of private agents and econometricians, and not directly observable to outsiders, and therefore, it is modeled as a latent factor. We allow for two regimes in policy rule coefficients specified as $a_{j}\left(s_{t}^{m}\right)=$ $a_{j, 0}\left(1-s_{t}^{m}\right)+a_{j, 1} s_{t}^{m}$ for $j=c, \pi$, and a regime switching occurs when monetary policy factor $w_{t}^{m}$ crosses threshold $\psi_{m}{ }^{5}$

\footnotetext{
${ }^{3}$ Davig and Leeper (2006a) consider an endogenous regime switching monetary policy model where the coefficients on inflation and output gap are specified as functions of the inflation threshold and lagged inflation in a New Keynesian model. Barthélemy and Marx (2017) consider a model that the monetary policy choice is determined by transition probabilities depending on the level of inflation to show conditions for the existence of a unique bounded equilibrium and solution method in regime switching rational expectations models with state-dependent transition probabilities. Their models, however, are not directly comparable to ours, which assumes regimes are determined by some unobserved economic fundamentals.

${ }^{4}$ There exists significant variation in policy rule specification. According to Rotemberg and Woodford (1999), the standard Taylor (1993) specification is nearly optimal in the class of models considered in their paper. Leeper and Roush (2003), Ireland (2004), and Sims and Zha (2006) argue that allowing money growth to enter the monetary policy rule is important for identifying policy behavior. Interest rate smoothing and expected inflation are widely considered in empirical literature as in Clarida et al. (2000). We seek to simplify the model to highlight the new endogeneity channel in regime switching policy rules in this paper. In our specification, we exclude output gap because of its potential measurement error and a substantial data revision emphasized in Kozicki (2004).

${ }^{5}$ Our model can be easily extended to allow for multiple regimes, but two states are considered enough to characterize policy coefficient switching in previous literature. According to Sims and Zha (2006), heteroskedastic errors are essential for fitting the U.S. data, and many authors also consider regime switching in volatility. Our approach may also allow to estimate policy rules with unsynchronized parameter and volatility switchings using a modified
} 
The monetary policy factor $w_{t}^{m}$ drives the regime change in our model and is assumed to evolve over time as an autoregressive process $w_{t}^{m}=\alpha_{m} w_{t-1}^{m}+v_{t}^{m}$, with autoregressive coefficient $\alpha_{m}$ indicating the degree of persistency in regime changes. Moreover, the past monetary policy disturbance $u_{t-1}^{m}$ and the current shock $v_{t}^{m}$ to policy factor are assumed to be jointly normal with unit variance and $\operatorname{cov}\left(u_{t-1}^{m}, v_{t}^{m}\right)=\rho_{m}$. In light of our earlier discussion, we may view monetary policy disturbance $u_{t}^{m}$ as the part of monetary policy instrument $i_{t}$ that is not predicted by monetary policy target variable $\pi_{t}$. Hence, $u_{t}^{m}$ is not an exogenous shock in the conventional sense from the policy maker's point of view; rather, it represents all other factors, such as monetary and other structural shocks and their entire history that may affect monetary policy decision, but that are not measured by the target variable $\pi_{t}$. Central banks may give weights to different economic conditions - including commodity prices, sluggish labor market development, stock market, and stance of fiscal policy - for a monetary policy decision with the occasion. Our interpretation of $u_{t}^{m}$ implies a view that the Fed's primary objective is to achieve low and stable inflation over the medium term, ${ }^{6}$ while at the same time, the Fed has reacted to emerging economic states purposefully and intermittently. ${ }^{7}$

Our specification explicitly allows for the aforementioned feedback channel in monetary policy rule. A part of the monetary policy disturbance $u_{t-1}^{m}$ incurred in the previous period will affect the change in policy choice $a_{\pi}\left(s_{t}^{m}\right)$ in the current period through its endogeneity, with the shock $v_{t}^{m}$ to the current monetary policy factor $w_{t}^{m}$ that determines the current state $s_{t}^{m}$ and monetary policy regime. Therefore, the degree of endogeneity $\rho_{m}$, more precisely $\left(1-\rho_{m}\right)$, can be interpreted as idiosyncratic considerations of central banks beyond the information embedded in the past monetary policy disturbance. We may observe that even the monetary policy regime changes are determined by the state of the economy, but the timing of regime changes may be not systematically determined to some degree. For example, the monetary policy regime change in 1980s may be an endogenous response to the state of the economy, high inflation leading to the appointment of inflation fighting central bank governors. But the timing of this monetary regime change might not be based on economic status only and possibly be influenced by political aspects.

Our monetary policy rule appears natural for policy analysis and subsequent interpretations. As in reality, policy authorities may adjust their policy behaviors based on the broad economic outlook and their own predictions about future economic states as well as on the entire history of policy instruments and targets. Therefore, we may naturally interpret the latent monetary policy factor as an internal information set used by the policy makers. The feedback channel established by endogeneity between next period policy regime factor and current policy disturbance in our

version of the filter by Chang et al. (2017). In this paper, we consider coefficient switching only to focus on policy interactions.

${ }^{6}$ See transcript of Federal Open Market Committee (September 17, 2015) for this terminology.

${ }^{7}$ Taylor (1993) [p. 202-203] states "What is perhaps surprising is that this rule fits the actual policy performance during the last few year remarkably well....There is a significant deviation (of the FFR to policy rule) in 1987 when the Fed respond to the crash in the stock market by easing interest rates." This statement supports our interpretation on $u_{t}^{m}$. 
model provides a sensible scheme with which policy makers may effectively utilize multiple sources of information on the economy for a purposeful policy, and thereby introduce constrained discretion to policy choice.

Contrary to monetary policy, there is no widely accepted specification for fiscal policy. ${ }^{8} \mathrm{We}$ specify fiscal policy rule that links the tax revenues $\tau_{t}$ net of transfer payments to government spending purchases $g_{t}$ and previous debt held by public $b_{t-1}$. Our fiscal policy specification is given as

$$
\tau_{t}=\beta_{c}\left(s_{t}^{f}\right)+\beta_{b}\left(s_{t}^{f}\right) b_{t-1}+\beta_{g}\left(s_{t}^{f}\right) g_{t}+\sigma^{f} u_{t}^{f},
$$

where $s_{t}^{f}$ represents a state process specifying a binary state of fiscal policy at $t$, with $s_{t}=0$ and 1 representing regimes which respond to the level of debt weakly and aggressively, respectively, and $u_{t}^{f}$ signifies fiscal policy disturbance. As in our model for monetary policy, we may let $s_{t}^{f}=1\left\{w_{t}^{f} \geq\right.$ $\left.\psi_{f}\right\}$, and use it to define our state dependent fiscal policy parameters as $\beta_{j}\left(s_{t}^{f}\right)=\beta_{j, 0}\left(1-s_{t}^{f}\right)+\beta_{j, 1} s_{t}^{f}$ for $j=c, b, g$. We also assume that latent fiscal policy factor $w_{t}^{f}$ follows $\operatorname{AR}(1)$ dynamics, $w_{t}^{f}=$ $\alpha_{f} w_{t-1}^{f}+v_{t}^{f}$. The fiscal policy factor shock $v_{t}^{f}$ and previous fiscal policy disturbance $u_{t-1}^{f}$ are jointly normal with unit variance and $\operatorname{cov}\left(u_{t-1}^{f}, v_{t}^{f}\right)=\rho_{f}$. As in the monetary policy rule specification, we allow for two states in fiscal policy coefficients, and interpret fiscal policy factor $w_{t}^{f}$ and endogeneity parameter $\rho_{f}$ in fiscal policy rule exactly as in our monetary policy rule.

Leeper (1991) defines regimes for monetary policy (MP) and fiscal policy (FP) depending upon the parameter values in monetary and fiscal policy equations. Monetary policy is defined to be active when it responds strongly to inflation by more than one-to-one with $\alpha_{\pi}>1$ in monetary policy rule (3), and passive when it responds weakly to inflation with $0 \leq \alpha_{\pi}<1$. Similarly, fiscal policy is defined to be passive when it reacts strongly to debt with the coefficient on debt $\beta_{b}$ in fiscal policy rule (4) strictly greater than real interest rate reflecting the cost of servicing the debt, and active when it reacts weakly to debt with $\beta_{b}$ less than real interest rate. We will use these definitions to interpret our subsequent empirical findings.

\subsection{Data and Estimation Results}

We use quarterly U.S. data from 1949:1 to 2014:2. To estimate the monetary policy rule (3), we set $\pi_{t}$ to be the inflation rate over contemporaneous and prior three quarters, as in Taylor (1993), and obtain inflation each period as log difference of GDP deflator. For the nominal interest rate $i_{t}$, we use three-month Treasury bill (T-bill) rate in the secondary market. ${ }^{9}$ For the estimation

\footnotetext{
${ }^{8}$ There are some studies of estimated fiscal rules, including Bohn (1998), Taylor (2000), Fatas and Mihov (2001), Auerbach (2003), Cohen and Follette (2005), Ballabriga and Martinez-Mongay (2005), Claeys (2004), Davig (2004), and Favero and Monacelli (2005).

${ }^{9}$ We use T-bill rate instead of federal funds rate (FFR) mainly because FFR is available publicly only from 1954:1. Using T-bill rate allows us to study regime changes in monetary and fiscal policy rules before 1954, which include important historic episodes such as Treasury Accord of March 1951 leading to passive monetary policy and the wartime fiscal financing for Korean War leading to active fiscal policy.
} 
of the fiscal policy rule in (4), we use fiscal variables for the federal government only. We let $\tau_{t}$ be the federal tax receipts net of total federal transfer payments as a share of GDP, and $b_{t}$ the market value of gross marketable federal debt held by public as a share of GDP, ${ }^{10}$ and $g_{t}$ the federal government consumption plus investment expenditures as a share of GDP. Monetary policy variables are obtained from Federal Reserve Bank of St. Louis, Economic Data-FRED, and fiscal policy variables from NIPA Table $3.2\left(\tau_{t}, g_{t}\right)$ and Federal Reserve Bank of Dallas, U.S. Economic Data and Analysis $\left(b_{t}\right)$.

Our regime switching monetary and fiscal policy rules are estimated by the maximum likelihood method using a modified Markov switching filter developed by Chang et al. (2017). Table 1 reports the maximum likelihood estimates, and Figure 1 presents the extracted monetary and fiscal policy factors $w_{t}^{m}$ and $w_{t}^{f}$ and estimated policy regimes that are determined by policy regime factors and thresholds.

Table 1: Estimation Results for Endogenous Regime Switching Policy Rules

\begin{tabular}{c|cc||c|cc}
\hline \multicolumn{2}{c||}{ Monetary Policy Rule } & \multicolumn{3}{c}{ Fiscal Policy Rule } \\
\hline Parameter & Estimate & S.E & Parameter & Estimate & S.E \\
\hline$\alpha_{m}$ & 0.983 & $(0.012)$ & $\alpha_{f}$ & 0.970 & $(0.020)$ \\
$\psi_{m}$ & -0.871 & $(1.843)$ & $\psi_{f}$ & -0.530 & $(1.185)$ \\
$\rho_{m}$ & 0.999 & $(0.001)$ & $\rho_{f}$ & 0.990 & $(0.025)$ \\
\hline$a_{c}\left(s_{t}^{m}=0\right)$ & 0.459 & $(0.276)$ & $\beta_{c}\left(s_{t}^{f}=0\right)$ & -0.028 & $(0.011)$ \\
$a_{c}\left(s_{t}^{m}=1\right)$ & 2.605 & $(0.255)$ & $\beta_{c}\left(s_{t}^{f}=1\right)$ & 0.012 & $(0.007)$ \\
$a_{\pi}\left(s_{t}^{m}=0\right)$ & 0.660 & $(0.067)$ & $\beta_{b}\left(s_{t}^{f}=0\right)$ & -0.033 & $(0.011)$ \\
$a_{\pi}\left(s_{t}^{m}=1\right)$ & 1.039 & $(0.061)$ & $\beta_{b}\left(s_{t}^{f}=1\right)$ & 0.056 & $(0.012)$ \\
& & & $\beta_{g}\left(s_{t}^{f}=0\right)$ & 1.027 & $(0.093)$ \\
& & & $\beta_{g}\left(s_{t}^{f}=1\right)$ & 0.602 & $(0.052)$ \\
$\sigma^{m}$ & 1.307 & $(0.059)$ & $\sigma^{f}$ & 0.014 & $(0.001)$ \\
\hline p-value(LR test for $\left.\rho_{m}=0\right)$ & \multicolumn{2}{|c|}{0.000001} & p-value $\left(\right.$ LR test for $\left.\rho_{f}=0\right)$ & 0.00024 \\
\hline
\end{tabular}

We may infer from the estimates of state-dependent parameters on inflation $\alpha_{\pi}$ given in the shaded area in the left panel of Table 1 that monetary policy switches between active with $\alpha_{m}>1$, when it responds strongly to inflation by more than one-for-one, and passive with $0 \leq \alpha_{m}<1$, when it responds weakly to inflation. In our model, policy regime is determined depending upon whether the extracted monetary policy factor $w_{t}^{m}$ is above or below the estimated threshold $\psi_{m}$, as shown in the left panel of Figure 1. Therefore, we may use the phrase 'active (passive) monetary policy regime' interchangeably with 'monetary policy factor is above (below) the estimated threshold'. The estimate of AR coefficient of monetary policy factor $\alpha_{m}$ is 0.983 , indicating strong persistency of monetary policy regime, and the estimate of endogeneity parameter $\rho_{m}$ is $0.999^{11}$, showing a strong and clear evidence of the existence of endogeneous feedback in monetary policy regime determination.

Our estimates from monetary policy rule imply that a positive monetary policy shock $u_{t}^{m}$ in

\footnotetext{
${ }^{10}$ We use the average debt-output ratio over previous four quarters as a measure of $b_{t-1}$.

${ }^{11}$ Here the current shock to the policy instrument would be fully transmitted to the latent monetary policy factor as our estimate of $\rho_{m}$ is virtually identical to 1 .
} 
Figure 1: Extracted Monetary and Fiscal Policy Factors and Estimated Policy Regimes
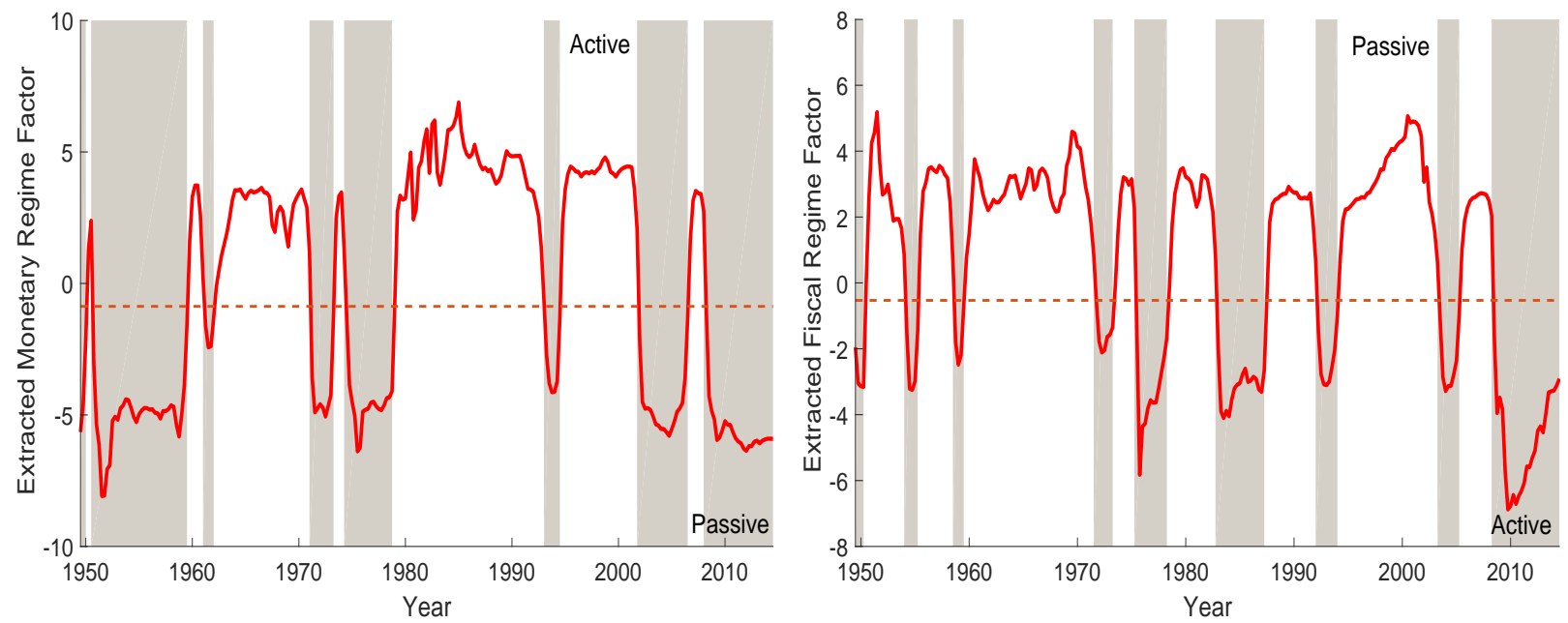

Notes: The solid and dashed lines on left-and right-hand-side graphs, respectively, present the extracted policy regime factors and corresponding thresholds from monetary (left) and fiscal (right) policy rules. The shaded areas on left and right panels indicate the passive monetary policy regime and active fiscal policy regime.

current period would forecast a higher monetary policy factor, which in turn implies that monetary policy is more likely to be active (less likely to be passive) in the next period. For example, if news contained in commodity prices portends higher future inflation, but does not yet affect inflation today, this positive shock would raise nominal interest rate above the level that current inflation predicts. A positive policy shock forecasts higher latent policy regime factor, which means a monetary authority would respond more aggressively to inflation in the next period.

The shaded area in the right panel of Table 1 shows that fiscal policy switches between passive and active by responding more than the real interest rate to debt or responding negatively to debt. Here we use the phrase 'active (passive) fiscal policy regime' interchangeably with 'extracted fiscal policy factor below (above) estimated threshold' as in the right panel of Figure 1. According to our estimation, fiscal policy reacts strongly to government spending, and responds weakly to debt in active regime. The estimate of $\alpha_{f}$ is 0.97 , implying that fiscal policy regime is also persistent but less persistent than monetary policy regime. The estimated value of the fiscal endogeneity parameter $\rho_{m}$ is also very high at 0.99 , indicating the presence of strong endogeneous feedback in fiscal policy regime switching. According to our estimates from fiscal policy rule, a positive fiscal policy shock $u_{t}^{f}$ leads to a higher forecast of fiscal policy factor, which in turn implies a higher likelihood of passive fiscal policy in future.

Table 6 provided in the Appendix presents the average values of policy instruments and target variables conditional on estimated regimes. We observe that the average real interest rate is higher in the active MP regime than in passive MP regime. Also, despite a higher average level of debt, average tax revenues are lower in the active FP regime than in passive FP regime, which means fiscal 
policy has behaved in active regime as the fiscal theory predicts on average. For both monetary and fiscal policy rules, the values of the maximum log likelihood from the endogenous switching model is larger than that from its exogenous counterpart, which has been considered frequently in previous empirical studies. Finally, we test for the presence of endogeneous feedback in regime switching using the likelihood ratio test and clearly reject the null of no endogeneous feedback at less than $1 \%$ significance level in both monetary and fiscal policy rules.

\subsection{Plausibility of Estimates}

We now examine the plausibility of our estimated policy rules in two ways - one based on the estimated policy parameters and the other on the estimated policy regimes. First of all, we note that our estimated policy rules fluctuate between theoretically interpretable regimes. Monetary policy fluctuates between active periods with the estimated policy parameter $a_{\pi}$ satisfying Taylor principle $a_{\pi}>1$, and passive periods with $0 \leq a_{\pi}<1$. Our estimated passive fiscal policy regime responds to debt strongly with a policy coefficient that exceeds most of the real interest rate estimates. Under passive fiscal policy, any increase in debt brings forth further surpluses that rise by real debt service plus a bit more to gradually retire the newly issued debt. Active fiscal policy, on the other hand, makes taxes relatively insensitive to debt, and according to our estimation of the policy parameter on debt, tax becomes even lower when debt increases.

Second, our estimated policy regimes seem quite consistent with narrative accounts of policy history. ${ }^{12}$ The left panel of Figure 2 shows the estimated passive monetary policy regimes (shaded areas) and historical data for T-bill and inflation rates. Except for the three brief periods in 1950:11950:2, 1959:3-1960:4, 1973:1-1974:2, and a longer period in 1962:1-1970:4, monetary policy was passive until October 1979 when the Fed changed operating procedures and responded to inflation aggressively. After 1980, monetary policy has been mostly active except for the two passive periods immediately after two recessions in 1991 and 2001. Monetary policy continued to weakly respond to inflation even after the official troughs of the downturns with sluggish labor market recoveries. Monetary policy became active when the Fed launched its preemptive strike against inflation in 1994. After the 2007-2008 financial crisis, monetary policy has become passive.

Our estimation results are also broadly consistent with previous empirical findings. At the beginning of our sample until Treasury Accord of March 1951, Federal Reserve policy supported high bond prices by keeping interest rates lower, even though consumer price index rose, indicating a passive monetary policy. During the entire 1950s, as the Korean War intensified, monetary policy largely accommodated the financing needs of fiscal policy (Ohanian (1997) and Woodford (2001)). The brief burst of active monetary policy late in 1959 is also consistent with the finding by Romer and Romer (2002) that the Fed raised real interest rate in this period to combat inflation. During the 1970s, we find that monetary policy regime was passive with explosive inflation rates as reported

\footnotetext{
${ }^{12}$ Narrative evidence draws on Pechman (1987), Poterba (1994), Stein (1996), Steuerle (2002), Romer and Romer (2004), and Yang (2007).
} 
Figure 2: Historical Data and Estimated Policy Regimes for Monetary and Fiscal Policy Rules
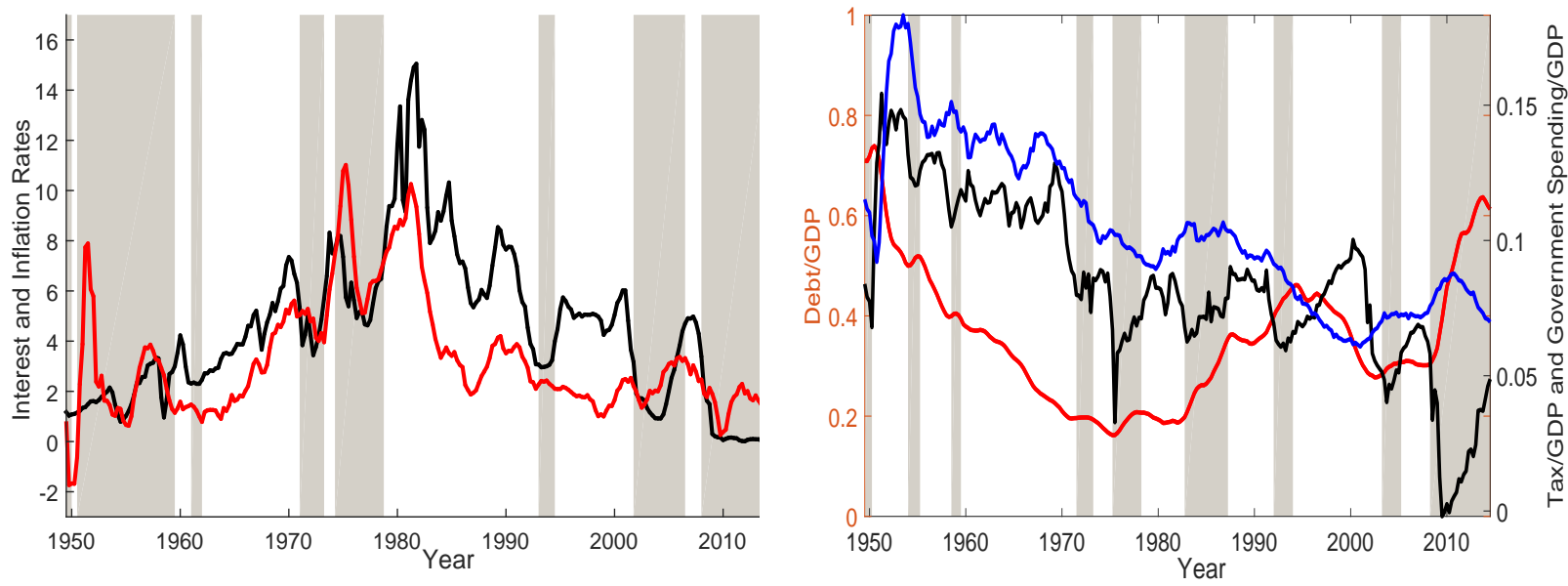

Notes: Left panel presents T-bill (black) and inflation rates (red) used in estimation of monetary policy rule, and shaded areas indicate passive monetary regime. The right panel presents tax/GDP ratio (black), debt/GDP ratio (red) and government spending/GDP ratio (blue) in estimation of fiscal policy rule, and shaded areas indicate active fiscal regime.

in previous empirical findings.

Since 1979, monetary policy was active except for two short periods following the recessions in 1991 and 2001. Our estimates indicate that monetary policy was passive during 1993:1-1994:1 and 2002:1-2006:2. As discussed in Davig and Leeper (2006b), there were prevailing concerns about low real interest rates and passive monetary policy behavior in the early 1990s and 2000s. During policy deliberations at the March 1993 FOMC meeting, which took place after the federal funds rate had been at 3 percent for several months, some governors expressed concern that the Fed was keeping the rate low for too long and dissented on the vote to maintain the funds rate at 3 percent (Board of Governors of the Federal Reserve System (1993)). Also, there are concerns related to negative real interest rates since 2001 and the flood of liquidity in 2003 and 2004 (Unsigned (2005a,b)).

Our estimates indicate that monetary policy regime was active during 2006:3-2007:4. Prior to 2006:3, interest rate had increased and was kept high until 2007:3. At the 2006 August meeting, Governor Lacker expressed that some inflation risks remained and he even preferred an increase of the federal funds rate target. Also, at the 2007 August meeting, the Committee's predominant policy concern continued to be the risk that inflation might fail to moderate as expected. For moderately elevated inflation, the FOMC had kept relatively high FFR target during this period based on concerns related to potential inflation pressure. ${ }^{13}$ After the recent financial crisis, monetary policy has become passive, and the target for FFR had been set at between 0 and $1 / 4$ percent by the end of our sample period.

The right panel of Figure 2 presents historical data on the fiscal variables we consider and the

\footnotetext{
${ }^{13}$ See FOMC statements released on August 8, 2006, and August 7, 2007.
} 
estimated active fiscal policy regimes marked as shaded areas. The fiscal policy regimes estimated from our regime switching fiscal policy rule with endogenous feedback accords well with the narrative accounts of the important historical episodes. Fiscal policy was active at the beginning of our sample period. Despite the extremely high level of debt from World War II expenditures, Congress overrode President Truman's veto of an income tax cut bill and passed the Income Tax Reduction Act of 1948. From 1950 to 1953, fiscal policy became passive, as income taxes, and excise taxes were raised and capital taxation were extended to finance Korean War. During the 1960s, fiscal policy became passive again with decreasing debt-to-GDP ratio. The 1974-1986 period contains at least three episodes of discretionary active tax policy: the 1975 fiscal expansion initiated by President Ford's tax cut following the oil price shock, the military build-up started by President Carter and strengthened during Reagan's presidency, and the 1982 tax cut by President Reagan (Favero and Monacelli (2005)). During this period, our estimates capture these episodes as active fiscal regimes.

In 1993, fiscal policy switched to being passive with President Clinton's tax hike, which is also referred as the Deficit Reduction Act of 1993. In subsequent tax reductions in 2002 and 2003 President Bush made fiscal policy active again. ${ }^{14}$ In 2008, Congress passed the Economic Stimulus Act to boost the economy from the recession after the 2007-2008 financial crisis and fiscal policy regime has been kept active.

\section{Policy Interactions}

There are two distinct regimes that permit monetary and fiscal policies to accomplish their two primary tasks of price level determination and debt stabilization (Sargent and Wallace (1981), Wallace (1981), Aiyagari and Gertler (1985), Sims (1988), and Leeper (1991)). While economic theory emphasizes how policies in a particular monetary and fiscal regime must interact to determine the price level uniquely, previous empirical studies in monetary and fiscal policy interactions tend to focus on dynamic patterns of correlation among policy variables (King and Plosser (1985), Melitz (1997, 2000), von Jagen et al. (2001), Muscatelli et al. (2002), and Kliem et al. (2016)).

Some recent works explore dynamic interactions between monetary and fiscal policy rules via exogenous regime switching models, rather than policy variables (Favero and Monacelli (2005), Davig and Leeper (2006b), Gonzalez-Astudillo (2013), and Bianchi and Ilut (2017)). This line of exploration gives an interpretation based on policy regime interactions that is consistent with what

\footnotetext{
${ }^{14}$ As argued in Davig and Leeper (2006b), recessions automatically lower revenues and raise debt, and we may naturally observe a negative correlation between taxes and debt. The negative response of taxes to debt in the active fiscal regime might therefore be regarded as a consequence of business cycles. Two active fiscal regimes, in the late 1940s and 1953:4-1955:1, almost exactly coincide with the cycle. However, there are extended periods of active fiscal policy, which include but do not coincide with recessions (2008:1-2009:2). There are also instances in which recessions occur during the periods of passive fiscal policy (1990:3-1991:1 and 2001:1-2001:4). Our estimation results show that active fiscal policy regime is not simply identified by recessions. More interestingly, during economic downturns, there is a tendency for the fiscal policy factor to decrease, thereby increasing the likelihood of fiscal policy to become active.
} 
economic theory emphasizes. However, most literature treats policy regime changes as exogenous, evolving independently of the state of the economy, and it is difficult to rationalize an exogenous policy change as an actual purposeful policy behavior and a systematic response to changes in the macroeconomic environment.

Under these limitations of previous empirical studies on policy interactions, we aim to explore a new empirical approach. We consider regime switching monetary and fiscal policy rules with endogenous feedback to describe purposeful policy behaviors where policy choices systematically respond to the state of the economy. And we examine policy regime interactions using policy regime factors that determine policy regimes explicitly in our policy rules.

As discussed earlier, we interpret latent policy regime factors as an internal information set of policy authorities, and each policy authority independently determines her policy rule based on her internal information. Estimated policy regime factors therefore can be interpreted as inferred factors representing observable part of internal information of policy makers, and we use them in our subsequent policy analyses as natural proxies for internal information of policy authorities.

Using extracted policy regime factors from monetary and fiscal policy rules, we may investigate not only regime changes in each policy rule but also systematic interactions between the two policy rules. Endogenous evolution of regime is an essential element in our analysis of policy interactions because it points research toward understanding how monetary policy's choice of its rule may influence fiscal policy's choice of its rule (and vice versa).

As an example, consider a conduct of monetary policy based on the review of economic and financial developments. In reviewing the economic outlook, the FOMC considers effects of the current and projected paths for fiscal policy on key macroeconomic variables such as GDP, employment, inflation, and others. In this way, fiscal policy has an indirect effect on the conduct of monetary policy through its influence on the state of the economy. Under the exogenous regime switching, however, we cannot sensibly analyze such dynamic interactions of policy regimes because policy regime evolves independently of endogenous economic variables.

\subsection{Understanding Policy Regime Factors}

We first aim to pin down the variables which explain the policy regime factors determining the regime switchings in the monetary and fiscal policy rules. This is because we interpret the policy regime factor as the policy makers' internal information set. To do so, we first relate our policy regime factor to macroeconomic and financial variables that are commonly considered in policy studies. To build a pool of the candidate macro-finance variables that may have explanatory power for policy regime factors, we start with the 113 quarterly macro time series considered in Koop and Korobilis (2010, KK hereafter) which are similar with only minor differences to the monthly variables considered in Bernanke et al. (2005, BBE hereafter) and Stock and Watson (2002, 2005, SW hereafter). We update the 113 quarterly time series in KK data set, which spans from 1959:1 to 2006:3, to 2014:2 to match with our sample span. 
We augment the KK data set with seven variables on personal consumption expenditures and stock prices that are considered in BBE but not included in the KK data set. They include four personal consumption expenditure series (total, services, nondurables, and durables) and three stock price indexes (Dow Jones Stock Average-30 Individual Stocks, S\&P Stock Price index-400 Industrials, and S\&P Stock Price Index-Composite Common Stocks). In addition, we add output gap, two extracted policy factors and six more fiscal variables to better understand whether and how monetary and fiscal regime factors are explained by macro and fiscal variables. The six additional fiscal variables include the ratios of net interest payment to government expenditure, net interest payment to debt, debt to GDP, government spending to GDP, military spending to GDP, and tax revenue to GDP. Policy instrument variables, short-term interest rate and tax revenue to GDP ratio, are excluded in our analysis of monetary and fiscal policy regime factors, respectively.

To effectively select a set of such macro-finance variables determining each of the inferred information indexes of policy authorities, we consider the aforementioned 129 variables as potential candidates and employ the adaptive LASSO (least absolute shrinkage and selection operator) method, a popular shrinkage regression method known to perform very well. A more detailed explanation on our implementation of the adaptive LASSO method is provided in the Appendix.

Table 2: Selected Variables for Monetary and Fiscal Policy Regime Factors

\begin{tabular}{c|c}
\hline Selected Variables for Monetary Factor & Category \\
\hline 10 year treasury rate & Interest rate \\
Tax/GDP ratio & Fiscal \\
Consumer price index: all items & Price indexes \\
Average weekly hours: manufacturing & Employment and hours \\
6 month T-bill minus federal fund rates & Interest rate \\
Net interest payment/ Govt.outlays & Fiscal \\
Extracted fiscal policy factor & Fiscal \\
\hline \multicolumn{2}{|c|}{} \\
\hline Selected Variables for Fiscal Factor & Category \\
\hline Extracted monetary policy factor & Monetary \\
\hline Output gap & Real output and income \\
\hline
\end{tabular}

Table 2 reports the selected variables for policy regime factors from adaptive LASSO. ${ }^{15}$ The top panel of Table 2 presents the seven variables from the selected model for the MP regime factor and the categories they belong. Interestingly, tax revenue to GDP ratio is selected as one of most important macro variables that may explain the level of monetary regime factor. Note that net interest payment to government expenditure ratio is also related to fiscal policy stance since the interest payment burden can be a strong incentive to change tax policy rules. There is a tendency that periods of increasing net interest payment to government expenditure ratio are matched with dates of significant legislation to increase taxes. Naturally, the variables that are commonly considered in the estimation of monetary policy rule are also selected with relatively large coefficient estimates. They include consumer price index, long term interest rate, and average

\footnotetext{
${ }^{15}$ Selected variables are listed in descending order by absolute value of estimated coefficients.
} 
weekly hours. Similarly, the bottom panel of Table 2 presents two variables from the selected model for the fiscal regime factor and the categories they are associated with. Extracted monetary policy factor and output gap are selected as most important variables to explain the fiscal regime factor.

The most important finding from the adaptive LASSO analysis is that the fiscal variables, tax to GDP ratio, net interest payment to government expenditures ratio and extracted fiscal policy factor, are selected to be most important variables explaining the monetary regime factor, and the extracted monetary policy factor is chosen to be significant for the fiscal regime factor with a larger estimated coefficient. Our findings here help us infer what policy makers consider in their decision making, and they show a clear, albeit indirect, evidence of policy interaction.

We note that the shrinkage regression analysis we use to select the variables explaining monetary and fiscal regime factors is static and based only on the contemporaneous relationship between the levels of policy regime factors and the variables reflecting the macroeconomic environment. We also study their dynamic interactions which is reported in a later section where we scrutinize the effects of policy regime shocks to various macro variables using a factor augmented VAR. In what follows, we first investigate how the regime factors themselves are interacting and how their interactions have evolved over time.

\subsection{Inter-Dynamics of Policy Regime Factors}

In this section, we consider a bivariate time varying coefficient VAR (TVC-VAR) model with extracted policy regime factors to investigate the interactions between monetary and fiscal policy authorities. In particular, we examine whether they have interacted to permit monetary and fiscal policies to deliver their primary policy goals. In identifying such policy regime interactions, we follow the notations in Leeper (1991), which provides a simple model in which the price level is jointly determined by monetary and fiscal policy regimes. Specifically, we consider two regimes: active monetary/passive fiscal regime $(\mathrm{AM} / \mathrm{PF})$ and passive monetary/active fiscal regime (PM/AF). In $\mathrm{AM} / \mathrm{PF}$ regime, central banks adjust the policy interest rate aggressively in response to inflation while the fiscal authority passively adjusts taxes and spending to ensure the fiscal solvency. On the other hand, in PM/AF regime, the fiscal policy nails down the real value of debt and the price level by making taxes unresponsive to debt while monetary policy passively permits jumps in the price level that stabilize debt.

Figure 3 presents the extracted policy regime factors from both monetary and fiscal policy rules. Since policy regime factors and thresholds determine policy regime changes in monetary and fiscal policy rules in our model, co-movement between two policy regime factors may provide useful information about the policy interactions. The correlation between two policy regime factors is 0.43. In our context, positive correlation means that, for example, if the monetary factor is more likely to be above the threshold (active monetary policy), then the fiscal factor is also more likely to be above the threshold (passive fiscal policy). The positive relationship between monetary and fiscal regime factors implies that there is a tendency for them to be active monetary/passive fiscal 
Figure 3: Extracted Policy Factors from Endogenous Regime Switching Policy Rules

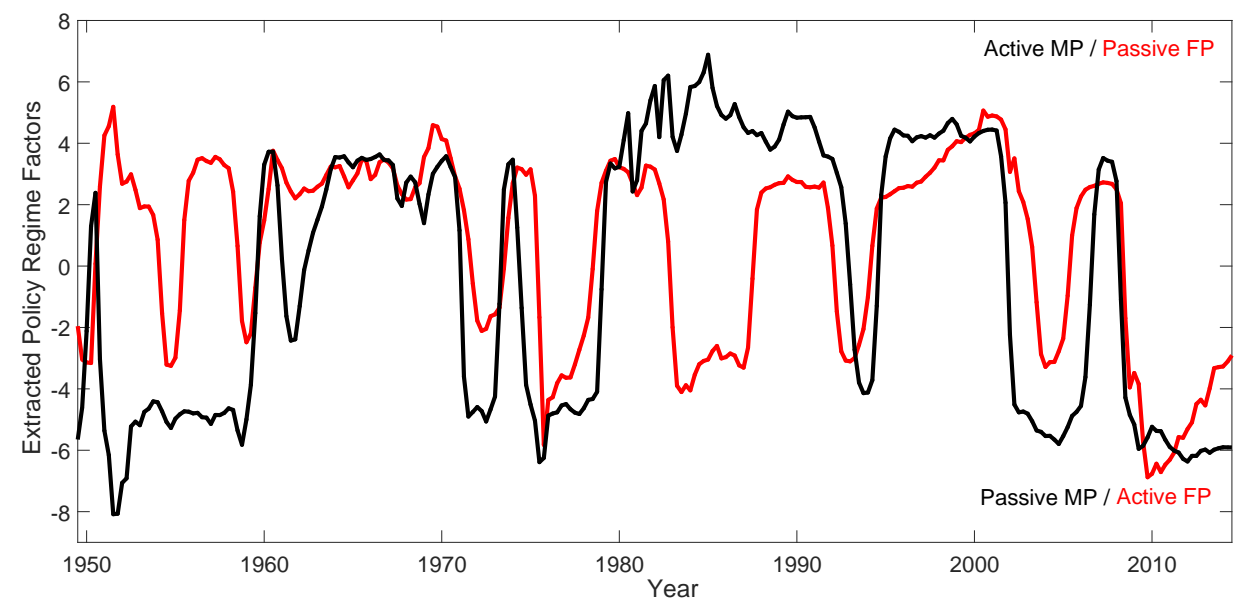

Notes: Figure 3 shows extracted monetary (black) and fiscal (red) factors from policy rules respectively.

or passive monetary/active fiscal which deliver a unique bounded equilibrium according to the aforementioned conventional monetarists view or the alternative fiscal theory of the price level.

As a preliminary analysis, we consider a time invariant VAR using policy regime factors. We consider the full sample period (1949:2-2014:2) and the recent subsample period (2000:1-2014:2), respectively. For the full sample period, average values of monetary and fiscal factors represent a combination of active MP/passive FP. For the recent subsample period, in contrast, average values of monetary and fiscal policy factors signify passive MP/active FP combination. ${ }^{16}$ Detailed estimation results from our time invariant VAR analysis are provided in Appendix for a comparison.

It is clear from our preliminary analysis that policy interactions have changed historically. Our result is consistent with the findings from previous empirical studies based on TVC-VAR models that also show that there exist fundamental changes in the U.S. economy over the last several decades. Among many, see Cogley and Sargent (2005), Primiceri (2005), and Gali and Gambetti (2009). To provide a more in-depth analysis of dynamic policy interactions, we also consider a TVC-VAR model with the policy regime factors extracted from monetary and fiscal policy rules. To estimate our TVC-VAR model, we use the classical kernel methods as in Giraitis et al. (2014, 2015) instead of Bayesian approach. ${ }^{17}$

More specifically, we consider the TVC-VAR model given by $y_{t}=A_{t} y_{t-1}+\eta_{t}$, where $y_{t}=$ $\left(w_{t}^{m}, w_{t}^{f}\right)^{\prime}, A_{t}$ is a 2-by-2 matrix of coefficient processes, and $\eta_{t}=\left(\eta_{t}^{m}, \eta_{t}^{f}\right)^{\prime}$ is the noise with

\footnotetext{
${ }^{16}$ The correlation between policy regime factors from monetary and fiscal policies during the subsample period is 0.77 which is greater than 0.43 in the full sample period. The subsample period includes the financial crisis and great recession.

${ }^{17}$ The usual advantages and disadvantages of the classical approach relative to the Bayesian approach are applicable for the comparison between our kernel method and the Bayesian VAR methodology. The kernel method is used here, since we follow the classical approach for all our empirical analysis in the paper.
} 
$E \eta_{t} \eta_{s}^{\prime}=0, t \neq s, t=1,2, \ldots T .{ }^{18}$ The time varying coefficient matrix $A_{t}$ is estimated as

$$
\widehat{A_{t}}=\left(\sum_{s=1}^{T} k_{t, s} y_{s} y_{s-1}^{\prime}\right)\left(\sum_{s=1}^{T} k_{t, s} y_{s-1} y_{s-1}^{\prime}\right)^{-1}
$$

with the weights $k_{t, s}=K\left((t-s) / H_{A}\right)$ given by the kernel function $K(x) \geq 0, x \in \mathbb{R}$, and the bandwidth parameter $H_{A}$. We use the Gaussian kernel, and the bandwidth parameter is chosen by the standard leave-one-out cross-validation (Stone (1974)) procedure. More specifically, we select $\widehat{H}_{A}$ minimizing $\sum_{t=1}^{T}\left\|y_{t}-\widehat{A}_{-t} y_{t-1}\right\|^{2}$, where $\widehat{A}_{-t}$ is an estimate of $A_{t}$ obtained by removing the observation pair $\left(y_{t}, y_{t-1}\right)$ for each $t$, and $\|\cdot\|$ denotes the standard Euclidean norm.

There is an important econometric issue in the estimation of TVC-VAR. As is well known, equations in a VAR with time-invariant coefficients may be estimated either individually as a univariate regression or systematically as a multivariate regression. The two approaches yield identical estimates. This is no longer applicable for a TVC-VAR model. The estimate of TVC is critically dependent upon the choice of kernel function and, in particular, bandwidth parameter. We estimate our TVC-VAR model using a system approach, which implies that we use the same kernel function with the same bandwidth parameter for all equations. Therefore, we effectively put restrictions on the choice of kernel and bandwidth across equations. It turns out that these are important restrictions. In fact, for individual univariate regressions, the cross-validation method picks too small bandwidth generating explosive dynamics. We believe that the system estimation extracts the common movement in a low frequency (with larger bandwidth) we want to analyze in the paper while the equation by equation estimation captures relatively high frequency dynamics (with small bandwidth).

Our estimation results are obtained from TVC-VAR(2). Given the coefficients allowed to vary nonparametrically over time, we think the second-order VAR is flexible enough to capture the dynamic interactions of the policy regime factors from our regime switching model. ${ }^{19}$ For the identification of the TVC-VAR, we employ a triangular scheme to orthogonalize the innovations, where we assume fiscal factor is contemporaneously affected by monetary factor but not vice versa. This scheme implies that monetary authority changes their policy stance first, and fiscal authority subsequently makes their policy decision after they observe the monetary policy changes.

In our TVC-VAR model, traditional impulse response functions are no longer an appropriate measure of responses because of time variation in the coefficients $A_{t}$. To properly take into account such time varying coefficients, we use the conditional impulse response functions suggested in Gambetti (2006) that determine the effects of a shock by the future time-varying coefficients,

\footnotetext{
${ }^{18}$ For the actual empirical analysis, we considered extended TVC-VAR models including the intercept term and additional lags. The required extension is straightforward.

${ }^{19}$ TCV-VAR(1) yields some awkward dynamics. All our results continue to hold in high-order VARs at least qualitatively, though the variability of estimates increases as we include more lags. Therefore, we choose TVC$\operatorname{VAR}(2)$ for parsimony in our specification.
} 
thereby rendering them dependent upon the time when the shock is given. ${ }^{20}$ Figures 4 and 5 present the responses of the policy regime factors to a negative one standard deviation shock to the monetary and fiscal factors respectively. For each quarter, we draw IRFs for horizons up to 20 quarters. In all 3-dimensional IRFs we report, quarters after the shock are on the $x$-axis, the time periods from 1949:2 to 2014:2 on the $y$-axis, and the values of the response on the $z$-axis. To focus on the time varying nature of IRF dynamics, we plot the IRFs starting from the estimated threshold levels for each quarter and use their signs and magnitudes to conveniently describe the direction and magnitude of the policy regime factor's responses to the given shock. The transparent blue surface in each figure represents the estimated threshold for corresponding policy rule reported in Table 1.

Figure 4: IRFs of Policy Regime Factors to MP Regime Shock in TVC-VAR
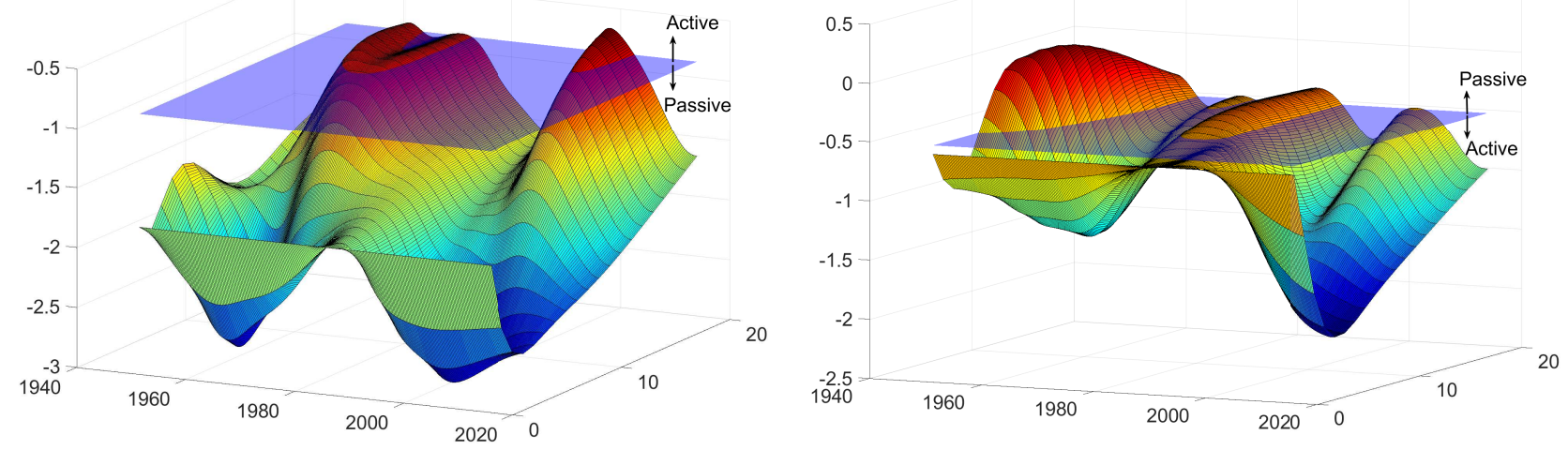

Notes: The left and right panels of Figure 4 respectively show the responses of MP factor and FP factor to negative MP regime shock that makes MP regime passive. Blue surface represents the corresponding threshold.

Figure 4 presents the responses of the policy regime factors to a negative shock to the monetary factor that makes monetary policy regime passive. The left-hand-side of Figure 4 shows that monetary policy rule becomes passive after the negative shock to monetary policy regime (monetary factor going under the threshold surface), and it remains passive for the next 20 quarters during most of the time periods we consider. This implies a stability in monetary policy behavior, which is particularly strong over the sample periods that includes the 1980s. This seems consistent with the common belief that the Fed kept a strong and consistent policy objective to control inflation during this period.

The right-hand-side of Figure 4 shows that fiscal policy becomes active (fiscal factor going under the threshold surface) after the negative shock on the monetary policy regime during most of our sample period except in the 1950s and 1980s when the fiscal factor moves up and stays above the

\footnotetext{
${ }^{20}$ For all out of sample coefficients needed for the computation of the conditional IRFs, we use the values of the coefficients at the end of the sample.
} 
threshold, making the fiscal policy regime also passive, a few quarters after the impact. Based on narrative accounts of policy history, in the 1950s and 1980s, the fiscal policy was known to be act independently of monetary policy stance due to its own purposes, the wartime fiscal financing and military build-up. Our results therefore show that, except during the 1950s and 1980s, the passive monetary policy regime shock drives fiscal policy toward an active regime, thereby producing a passive monetary/active fiscal combination that delivers a determinate, well-behaved equilibrium according to the fiscal theory of price.

Figure 5: IRFs of Policy Regime Factors to FP Regime Shock in TVC-VAR
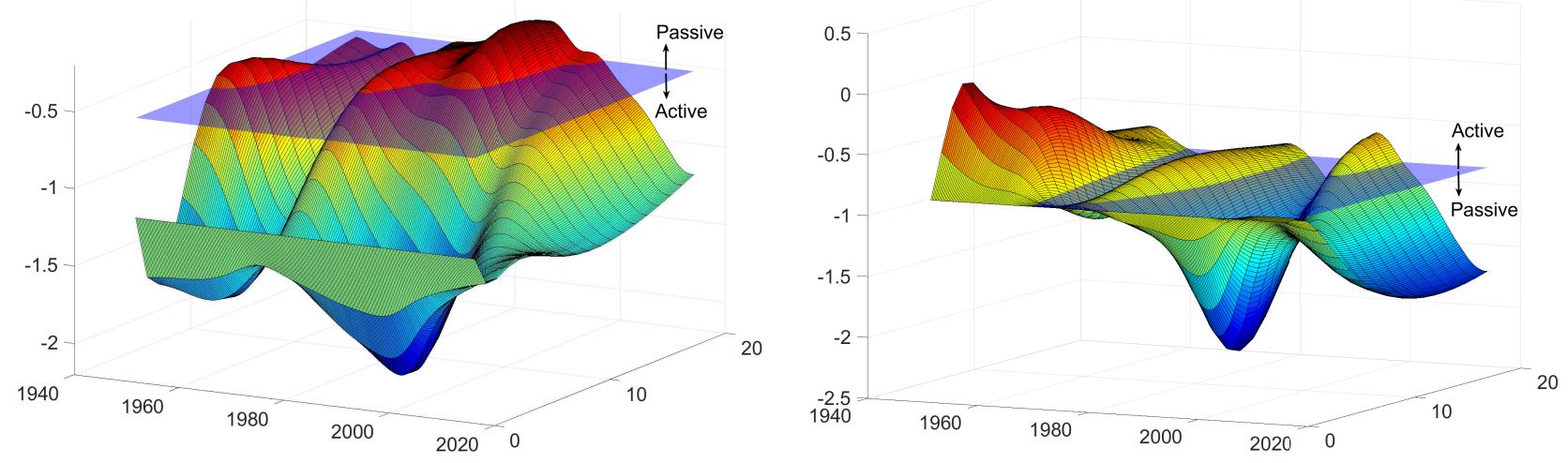

Notes: The left and right panels of Figure 5 respectively show the responses of FP factor and MP factor to a negative FP regime shock that makes FP regime active. Blue surface represents corresponding threshold.

Figure 5 shows the responses of policy regime factors to a negative shock to fiscal factor which makes fiscal policy regime active. The left panel of Figure 5 shows that with the negative shock to fiscal regime factor, fiscal policy becomes active (fiscal factor going under the threshold surface) in most of the sample period, suggesting a persistent fiscal policy behavior. There are, however, three short periods in the 1950s, 1970s, and 1980s where fiscal regime moves up above the surface and stays there for several quarters, implying that the fiscal policy becomes passive during these periods. On the other hand, the right panel of Figure 5 shows the response of the monetary policy factor to the active fiscal policy regime shock. It is clearly shown that the monetary policy responds to the fiscal policy shock, though the direction of the response is opposite before and after the 1980s. When fiscal policy regime becomes active, monetary policy also becomes active or responds insignificantly before the 1980s, while monetary policy becomes passive after the 1980s. Especially in the 1950s monetary policy tends to also become active. When fiscal policy is active, more active monetary policy that responds strongly to inflation will be destabilizing since it amplifies the impacts of a negative fiscal policy shock to taxes. The doubly active policy mix, according to Leeper (1991), stabilizes neither inflation nor debt.

During the 1990s and 2000s, estimated policy regimes were mostly active monetary/passive 
fiscal. Leeper (1991) shows that under this Ricardian equivalence combination of policy regimes, any fiscal disturbance leaves the present value of current and expected future primary surpluses unchanged, and hence, the output, inflation, and nominal interest rate are also unchanged. However, after an active fiscal policy shock, monetary policy tends to become passive after the 1980s. Our empirical finding supports a finding in Davig et al. (2004) and Davig and Leeper (2006b): the fiscal theory is operating whenever economic agents believe it is possible for fiscal policy to become active with ongoing regime change, even when the rules in place at a given moment would suggest that Ricardian equivalence should hold if regime were fixed. A central bank that does not account for on-going regime change, therefore, would mistakenly interpret higher inflation as due to some demand shocks other than fiscal policy.

Our estimation results indicate that the interaction between monetary and fiscal policies has become stronger in the recent sample period since 2008. We see clearly that fiscal policy tends to be more active when monetary policy becomes passive, and monetary policy seems to be more passive when fiscal policy becomes active during this period. Since the financial crisis and great recession, the monetary and fiscal policy interactions seem apparent, as can be inferred from the recent expansions of central bank balance sheets with several rounds of quantitative easing (QE) and surging levels of sovereign debt.

Finally, we consider impulse response functions on selected years and impulse response horizons to better understand how they evolve over horizons on selected time periods, and also over time at selected horizons. Figure 11 in the Appendix shows the impulse responses of policy regime factors to a negative shock to policy regimes on selected years. Presented in the first two columns of Figure 11 are the impulse responses of monetary and fiscal factors to this negative monetary regime shock given in the first quarters of 1965, 1982, 2005, and 2013. As shown in the first column, effects of monetary regime shock live longer in 1982 and 2013 than in other selected years. The second column presents the impulse responses of fiscal factor to monetary regime shock on the same selected years. Overall, when the monetary policy regime becomes passive, the fiscal policy regime tends to become more active but the magnitude and persistency of the responses vary across different time periods. In terms of the magnitude of the response, fiscal policy responds weakly to the monetary policy shock in 1982 compared to other selected years we consider. In 2013, however, the fiscal policy regime becomes active with a large magnitude of response and the persistency of shock effect.

The last two columns of Figure 11 show the impulse responses of policy regime factors to a negative shock to the fiscal regime that makes fiscal policy regime active on selected years. The third column presents the impulse responses of fiscal factor to this active fiscal regime shock given in the first quarters of 1955, 1982, 2005, and 2013. In 2005 and 2013, effects of fiscal regime shock live longer than in other selected years. The fourth column presents the impulse responses of monetary factor to the shock to fiscal regime. Before the 1980s, the monetary policy regime is mostly active even when fiscal policy regime becomes active. From the early 1980s, monetary 
policy regime becomes passive when fiscal policy regime becomes active, and the magnitudes of responses increase further after 1990s. ${ }^{21}$

Figure 12 in the Appendix presents how effects of policy regime shock evolve over time at the two selected horizons, 5 and 15 quarters after the initial policy regime shock. The four columns show from left to right the impulse responses of monetary policy regime to monetary regime shock, of monetary policy regime to fiscal regime shock, of fiscal policy regime to fiscal regime shock and of monetary policy regime to fiscal regime shock. The top panels show the impulse responses 5 quarters ahead from the initial shock given at each year in our sample period, while the bottom panels show the responses at 15 quarters after the initial shock. The second column clearly shows that fiscal policy regime becomes active after the 1990s when the monetary policy regime becomes passive, and the magnitude of responses has increased after 15 quarters from the initial monetary regime shock. As discussed earlier, the fourth column shows that the monetary policy responds to the fiscal policy regime shock differently before and after the 1980s.

In this section, we have demonstrated how we may use the policy regime factors extracted from our endogenous regime switching policy rules to investigate the dynamic interaction between monetary and fiscal policy rules using a TVC-VAR model. We find that the patterns of monetary and fiscal policy interactions have changed during the past six decades and that the degree of interactions between two policy authorities has become stronger in the recent years.

\section{Linking Policy Regime Factors to Macro Economy}

In this section, we study how the policy factors are related to macro variables. Changes in policy regime factors may influence the macro economy in two ways. First, changes in policy regimes influence the economy directly via changes in interest rate and tax. Second, changes in policy regime factor influence the economy through the economic agents' beliefs or expectations about current and future policy regimes. Policy regime factors are related to policy disturbances that are policy changes not driven by inflation rate for monetary policy and by debt level and government spending for fiscal policy, so they reflect other systematic but not explicitly modeled aspects of actual policy behaviors. To private agents, policy disturbances signal possible policy regime changes in the future by altering policy instruments more or less aggressively than the usual policy target variables imply.

Economic agents make an inference about underlying policy regimes via policy regime factors in our model. Since the latent policy regime factors are not observable, economic agents estimate

\footnotetext{
${ }^{21}$ Kliem et al. (2016) argue that the low-frequency relationship between primary deficits over debt and inflation has become insignificant after 1980 as the Fed kept active regime independently after 1980. However, we observe a strong interaction between policy regime factors with a large magnitude of responses after the 1990s. This is in sharp contrast to previous findings in the empirical policy interaction literature including Kliem et al. (2016). We exclude the period after 2008 and re-estimate our TVC-VAR to check whether policy interactions during the 1990s and 2000s may be misled by a strong policy interaction after 2008 in our estimation. However, we still find similar interactions between monetary and fiscal policies, for the subsample period (1949:2-2007:4).
} 
them to make an inference about current and future policy regimes as econometricians do. The estimated policy regime factors can therefore be interpreted as the quantified agents' beliefs on the stance of policy authorities. When there is a change in the inferred policy regime factors, it will affect the transition probabilities of policy regime changes, and rational economic agents will reoptimize their lifetime utility accordingly. Through this channel, changes in policy regime factors have effects on various macro variables.

We analyze responses of policy regime factors to shocks from macro variables using VAR with six selected variables in Section 4.1. We also investigate effects of changes in policy regime factors to some key macroeconomic variables by using factor augmented VAR (FAVAR) in Section 4.2. By investigating the interactions among policy regime factors with macro variables, we may provide some meaningful implications for constructing a dynamic stochastic general equilibrium (DSGE) models relevant for policy interactions and macroeconomy.

\subsection{Key Non-Policy Variables}

In this section, we consider a small-scale structural model to investigate the effects of non-policy shocks to policy regimes and their interactions. ${ }^{22}$ Specifically, the structural form considered in this section is $\sum_{s=0}^{p} A_{s} y_{t-s}=\epsilon_{t}$, where $y_{t}$ is an $m$ by 1 vector of time series and $\epsilon_{t}$ is a vector of i.i.d structural disturbances that are exogenous to the model. Those disturbances hit both non-policy and policy sectors of the economy, and accordingly we let $\epsilon_{t}=\left(\epsilon_{N t}^{\prime}, \epsilon_{P t}^{\prime}\right)^{\prime}$, where $\epsilon_{N t}$ and $\epsilon_{P t}$ are the vectors of non-policy and policy disturbances, respectively. We estimate an identified VAR including four non-policy variables (output gap, GDP deflator, 10 year T-bill rate, and commodity price index) and two policy variables (monetary and fiscal regime factors). Two goods market variables, the output gap (Y) and GDP deflator (PI), represent the real activity and price level. We consider the long term interest rate, the 10 year T-bill rate (10YTR), as a financial variable. Commodity price index $(\mathrm{CP})$ represents an information variable that reacts instantaneously to shocks from other sectors of the economy. As policy variables, we add monetary and fiscal regime factors.

The identification treats the output gap and price level as predetermined for the rest of the system, reflecting the view that producing and pricing decisions do not respond immediately to shocks from other sectors. The financial and information variables are naturally assumed to respond to goods market variables contemporaneously, and accordingly we specify that policy authorities set their policy stances based on the information from goods market variables, long term interest rate and commodity prices within the quarter. The data used in this section are the same as those used in Section 3. All variables are in first differences of logarithms except for the output gap, long term interest rate, and policy regime factors. We estimate our model with 5 lags. ${ }^{23}$

\footnotetext{
${ }^{22}$ Actual monetary and fiscal policy behaviors may be based on a high-dimensional vector of macroeconomic and financial variables. Here, however, we focus on the effects of non-policy regime shocks to policy regimes, and simply consider several variables based on the previous empirical findings.

${ }^{23}$ Adding more lags gives the similar results with more fluctuations in impulse responses.
} 
Figure 6: Impulse Responses of All Variables in VAR Model
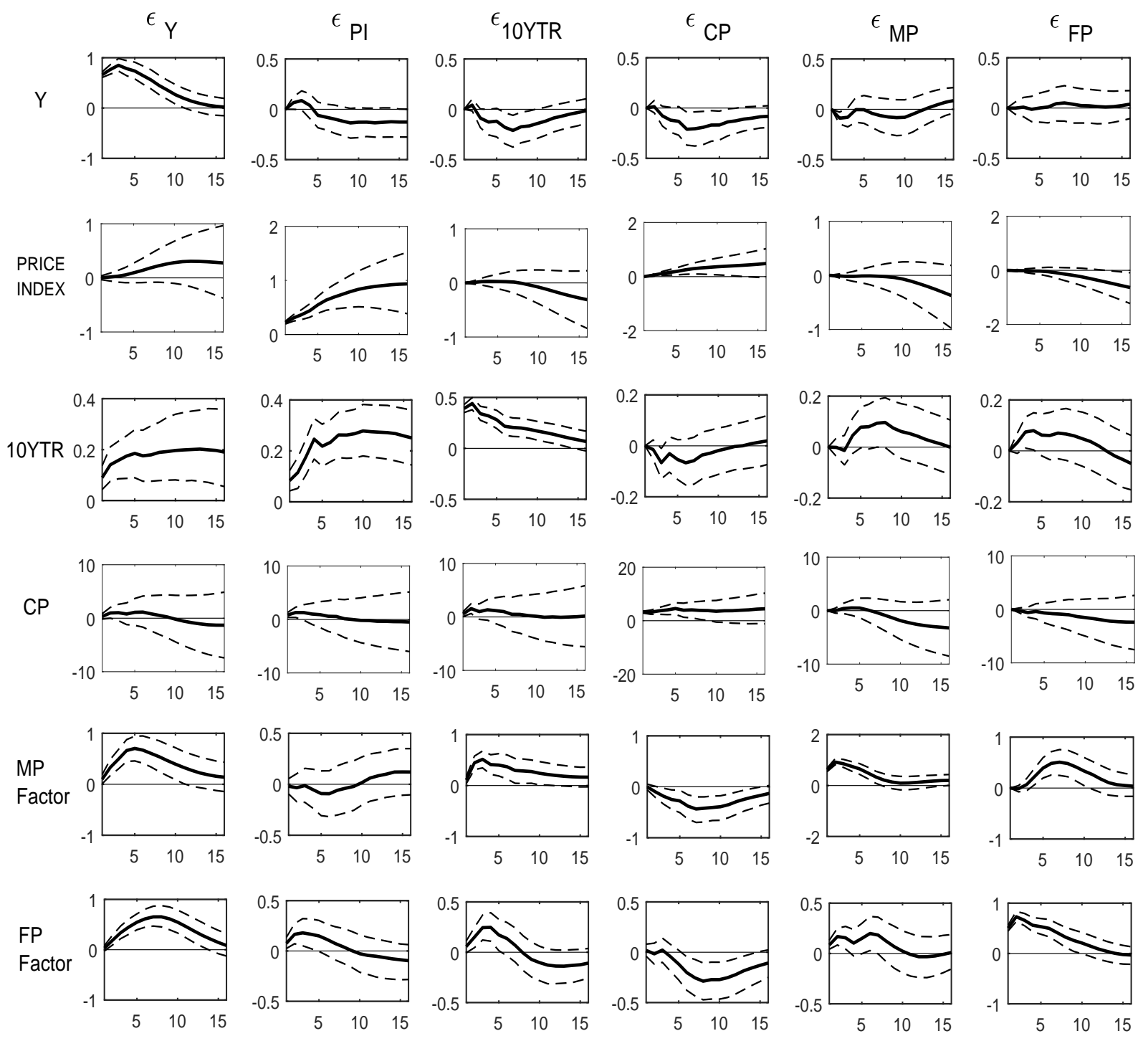

Notes: The $x$-axis represents quarters after the shock, the $y$-axis represents the value of the impulse responses (in percent) to a positive one standard deviation shocks to variables. The upper and lower dotted lines represent the $90 \%$ confidence intervals of impulse responses.

Figure 6 reports responses of all six variables to each of the six exogenous disturbances. The first column shows the responses to positive one standard deviation shock to output gap. The positive shock to output gap generates an inflationary gap indicating that the growth of aggregate demand is outpacing the potential GDP at full employment. A positive output gap possibly increases inflation as shown in the second row. With the positive shock to output gap, price level increases, and long term interest rate also increases as a compensation for the inflation risk. The commodity price index increases slightly. With the inflationary gap, the monetary policy regime becomes active. Under this positive output gap shock, the fiscal policy regime becomes passive and increases tax 
by responding strongly to debt level and weakly to government spending. Shocks to real activities generate clear policy interaction which is consistent with our empirical finding. In the second column, we see that a positive shock to price level increases price level and long term interest rate, compensating for an inflation risk. The higher price level reduces consumer purchasing power, causing aggregate demand to fall. The response of monetary policy regime factor is unclear with a wide error band on response due to the mixed effects from price level and output gap responses, while fiscal policy regime becomes passive initially.

The third column shows that when the long term interest rate increases, the price level decreases with some lags. Monetary policy regime becomes active for a long time, and fiscal policy regime becomes passive initially. Output gap becomes negative quickly with active MP and passive FP. In the fourth column, when the commodity price index increases, responses of monetary policy regime factor decreases, and fiscal policy regime factor also decreases with mixed effect from the increasing price level and decreasing output gap. We observe here that impulse responses of two policy factors to a positive real activity shock are consistent with a policy regime interaction which delivers a determinate and well-behaved equilibrium in economic theory in terms of the sign and magnitude. The dynamics of policy regime factors' responses to the non-policy structural shocks may vary, but overall those non-policy shocks also generate the initial responses in the same direction as the shocks to policy factors.

The fifth and sixth columns present the effects of each policy shock to non-policy variables and the other policy factor. When monetary policy regime becomes active, fiscal policy regime becomes passive, and output gap decreases initially. After a few quarters, however, responses of output gap become unclear with a wider error band. Price level decreases with some lags and long term interest rate increases during the first 8 quarters but then starts to decrease as price level decreases. Commodity price index also decreases as price level decreases. The last column shows that to a passive fiscal policy regime shock, output gap responds unclearly with a wide error band, price level decreases with some lags, long term interest rate increases initially and then decreases as price level decreases, and monetary policy regime becomes active during the entire 16 quarters. Overall, impulse responses of macro variables and policy regime factors to both non-policy and policy shocks are consistent with our prior expectations.

Table 3: Contributions (\%) of Structural Shocks to Forecast Error Variances

\begin{tabular}{|c|c|c|c|c|c|c|}
\hline & \multicolumn{7}{|c|}{ Structural Shocks } \\
\hline Variables & $\epsilon_{Y}$ & $\epsilon_{P I}$ & $\epsilon_{10 Y T R}$ & $\epsilon_{C P}$ & $\epsilon_{M P}$ & $\epsilon_{F P}$ \\
\hline Y & 84.7 & 2.6 & 4.5 & 7.0 & 1.1 & 0.1 \\
\hline PI & 24.5 & 54.8 & 3.2 & 5.9 & 5.5 & 6.1 \\
\hline 10YTR & 25.2 & 34.3 & 36.1 & 0.9 & 2.0 & 1.6 \\
\hline CP & 6.3 & 8.2 & 9.4 & 63.6 & 8.4 & 4.0 \\
\hline MP & 29.0 & 0.6 & 12.7 & 15.4 & 30.5 & 11.9 \\
\hline FP & 47.0 & 2.0 & 4.1 & 10.3 & 2.4 & 34.2 \\
\hline
\end{tabular}


Table 3 presents the results from variance decomposition of forecast errors for each variable at the 16 quarter horizon. We observe that only $31 \%$ and $34 \%$ of the forecast error variances of monetary and fiscal policy factors are attributed to their respective innovations. This implies that most of the error variances of MP and FP regime factors are attributed to the shocks other than their own innovations. In particular, the shock to output gap alone explains $29 \%$ and $47 \%$ of the forecast error variances of monetary and fiscal policy regime factors, respectively. The shocks to long term interest rate, commodity price index, and fiscal policy factor also contribute significantly to explaining the error made in forecasting the monetary policy factor. We also find that the shocks to macro variables and monetary regime factor are important factors explaining the forecast error of the fiscal policy factor. Our results imply that policy regime factors evolve endogenously interacting not only with each other but also with other non-policy structural shocks to macroeconomy.

From our structural VAR analysis, we find that the shock to output gap contributes significant fractions of forecast errors in most of the variables we consider. We also observe that the shock to commodity price index explains more fractions of the error in the forecast of the policy regime factors than the shock to the price level explains. The commodity price index is commonly considered as an indicator of future inflation since it is quick to respond to economy-wide shocks to demand. In this sense, it is natural that policy regime factors are more closely related to commodity price index than the usual price index.

\subsection{Leading Macro Factors}

In this section, we examine how the policy regime factors interact with key macroeconomic variables using factor augmented VAR (FAVAR) introduced in Bernanke et al. (2005). We continue to consider the same set of variables used in our adaptive LASSO estimation presented earlier in Section 3 , but with a different objective. While we try to learn which variables are linked to the policy regime factors in the adaptive LASSO analysis, we now investigate how the changes in the policy regime factors affect key macroeconomic variables such as inflation, GDP, unemployment, and others. In our endogenous regime switching model, policy regime factors systematically respond to policy shocks due to the endogeneity between policy shocks and innovations of policy regime factors. The values of the policy regime factors in the next period move up or down depending on the realized policy shock in the current period, and policy rules switch correspondingly either from passive to active or from active to passive. Such systematic changes in policy rules will certainly influence the macroeconomy. Of course, the change in the policy regime factor may not be big enough to cause policy rule to change, but it may still influence macroeconomy through the expectation effect that we discussed earlier.

As in BBE, we assume that the time series $X_{t}$ containing all 127 macro variables we consider here are related to the policy regime factors as well as the leading components of $X_{t}$, viz.,

$$
X_{t}=\Lambda C_{t}+e_{t}=\Lambda^{f} F_{t}+\Lambda^{w} W_{t}+e_{t}
$$


where $W_{t}$ represents the monetary and fiscal policy regime factors, $F_{t}$ the principal components of $X_{t}$ net of the effect from $W_{t},{ }^{24}$ and $e_{t}$ an error term. The economy is therefore assumed to be affected by both $F_{t}$ and $W_{t}$ via their influence on all of the macro and financial variables included in $X_{t}$. We may interpret the leading factors $F_{t}$ extracting additional information on general macroeconomic environment from the variables contained in $X_{t}$ beyond the information already captured by our policy regime factors. The joint dynamics of the common component $C_{t}=\left(F_{t}, W_{t}\right)$ are assumed to follow a finite order invertible VAR process as $\Phi(L) C_{t}=v_{t}$, which can be written as an infinite order vector MA process as $C_{t}=\Phi(L)^{-1} v_{t}$, where $v_{t}$ is a white noise process. Then we have $X_{t}=\Lambda \Phi(L)^{-1} v_{t}+e_{t}$, where $\Lambda \Phi(L)^{-1}$ contains the impulse responses of each variable in $X_{t}$ to shocks in the common components $F_{t}$ and $W_{t}$. We assume that the common components $F_{t}$ and $W_{t}$ jointly capture systematic movements in $X_{t}$, and the error process $e_{t}$ can be viewed as idiosyncratic measurement errors.

We compute impulse response functions for each variable in $X_{t}$ to a shock in the policy regime factors $W_{t}$ and their confidence intervals via bootstrapping, following the two-step principal component approach used in Bernanke et al. (2005). The two-step approach implies the presence of generated regressors in the second step. According to Bai (2003), the uncertainty in factor estimation is negligible when the number $N$ of variables included in $X_{t}$ is large relative to the sample size $T,{ }^{25}$ which does not hold in our case with $N=127$ and $T=261$. To account for the uncertainty in the factor estimation, we use the double bootstrapping procedure suggested in Kilian (1998) to compute the confidence intervals for the impulse response functions.

To implement FAVAR in our context, we use the extracted monetary and fiscal policy factors, and five leading principal components from 127 macroeconomic variables. For the structural identification, we assume that monetary and fiscal regime factors are contemporaneously affected by the five macro leading factors. For the ordering of monetary and fiscal regime factors, we assume as in our earlier TVC-VAR analysis that monetary policy makers set its policy stance first and fiscal policy authority subsequently makes its policy decision. We consider VAR(5) for the joint dynamics of the common factors $C_{t}$.

Our main results are shown in Figures 7-8. Each figure presents impulse responses of policy regime factors and some selected key macroeconomic variables to the shocks to policy regime factors with $90 \%$ confidence intervals. ${ }^{26}$ The left panel of Figure 7 shows that a positive one standard deviation shock to monetary policy factor increases both monetary and fiscal policy factors, making monetary and fiscal policy regimes more likely to become, respectively, active and passive.

The effects of this active monetary regime shock on the selected macro variables are shown in the right panel of Figure 7. It decreases GDP and increases unemployment rate with a wide error

\footnotetext{
${ }^{24}$ To obtain the principal components $F_{t}$ orthogonal to $W_{t}$, we first obtain the principal components $F_{t}^{o}$ from $X_{t}$, and fit $X_{t}$ by the ordinary least squares (OLS) regression as $X_{t}=\hat{\Lambda}_{o}^{f} F_{t}^{o}+\hat{\Lambda}_{o}^{w} W_{t}$. Then obtain $F_{t}$ as the principal components of $X_{t}-\hat{\Lambda}_{0}^{w} W_{t}$.

${ }^{25}$ Specifically, $\sqrt{T} / N \rightarrow 0$ is required to hold as $N, T \rightarrow \infty$.

${ }^{26}$ The confidence intervals are obtained from 100,000 bootstrapped impulse responses.
} 
Figure 7: Responses of Policy Factors and Key Macro Variables to MP Regime Shock in FAVAR
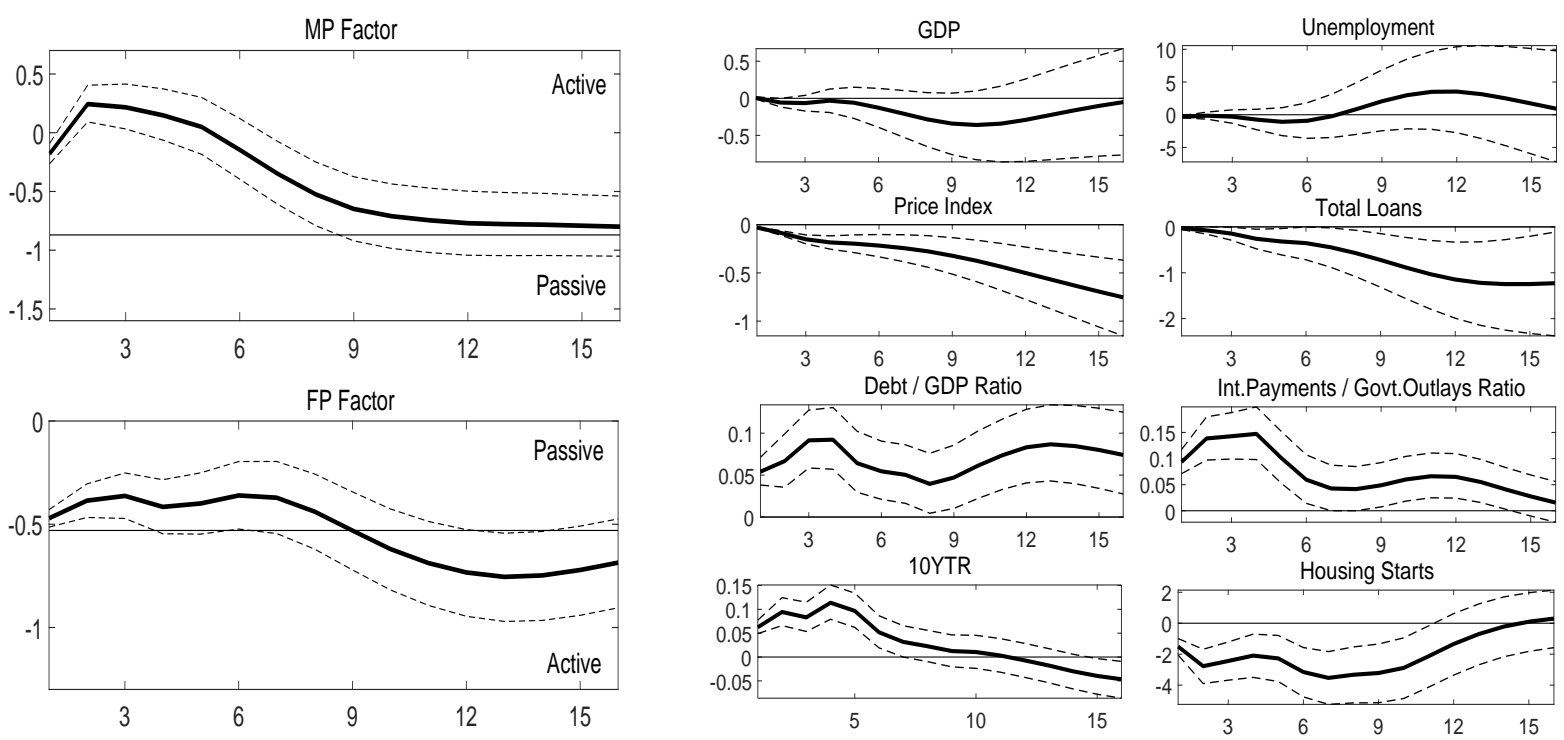

Notes: Figure 7 shows the impulse responses of policy factors to MP regime shock (left) that makes monetary policy regime active and impulse responses of key macro variables to MP regime shock (right), respectively.

band including the base line. The price level decreases consistently during the entire horizon. ${ }^{27}$

We also observe a similar decline in total loans from commercial banks. As the probability of having more active monetary policy regime increases, debt to GDP ratio increases as GDP decreases. Net interest payment to government outlays ratio increases initially but then starts to decrease due to the combined effects from debt to GDP ratio and interest rate.

With the active monetary regime shock, long-term interest rate (10 year T-bill rate) increases initially but decreases after 12 quarters. As monetary policy becomes active and fiscal policy becomes passive, new housing constructions decrease through two possible channels. First, a rise in interest rates would increase the cost of housing capital, which would reduce demand for housing services and put downward pressure on the price of housing units. The depression of real housing prices would impede new investment in housing, and the volume of new housing start would fall. Second, with an increase in taxes, say a personal income tax and a corporate profit tax, disposable income decreases and investment and employment also decrease, which reduces aggregate demand and subsequently volume of new housing start. ${ }^{28}$

We now discuss the effects of a passive fiscal policy shock on the policy regime factors and the aforementioned key macro variables. After a positive one standard deviation shock to fiscal

\footnotetext{
${ }^{27}$ Here we use GDP deflator as price level since we compute inflation rate using GDP deflator in our estimation of monetary policy rule. We also used other measures of price level (producer and consumer price indexes), but the resulting responses were similar.

${ }^{28}$ There may be many other plausible explanations for interactions between housing starts and monetary and fiscal policy regimes. Clearly, the housing market is one of the important transmission channels which links the macro economy and policy regime effects.
} 
Figure 8: Responses of Policy Factors and Key Macro Variables to FP Regime Shock in FAVAR
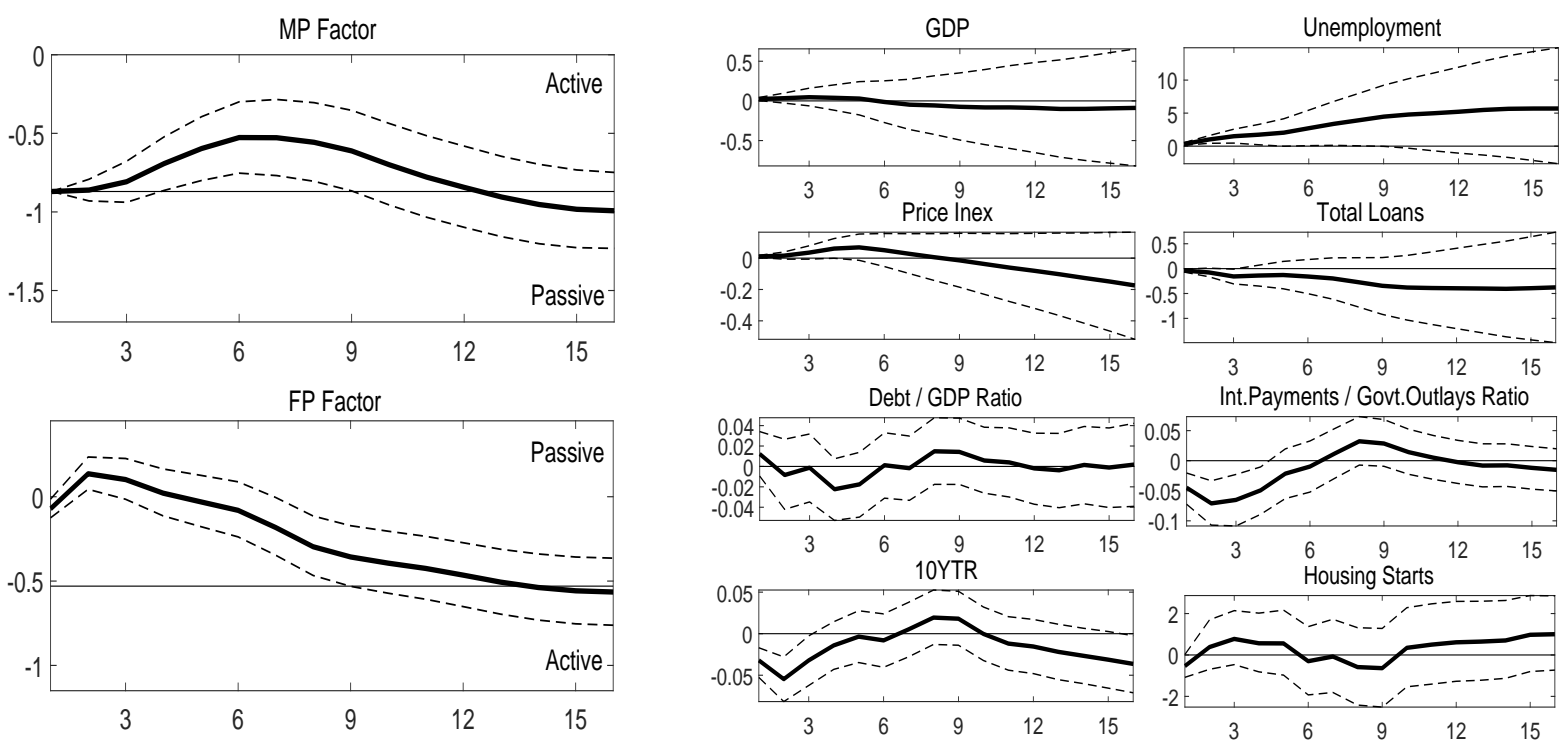

Notes: Figure 8 shows the impulse responses of policy factors to FP regime shock (left) that makes fiscal policy regime passive and impulse responses of key macro variables to FP regime shock (right), respectively.

regime factor, fiscal and monetary policy regimes become more likely to be passive and active, respectively, as shown in the left panel of Figure 8. With these higher likelihood of monetary and fiscal policy regimes becoming active and passive, the right panel of Figure 8 shows that GDP decreases, unemployment increases with a wide error band and some lags, and inflation rate decreases with some lags. Debt to GDP ratio fluctuates with a wide error band and net interest payment to government outlays ratio decreases. Long term interest rate starts from a negative value and increases gradually, and then decreases. Total loans decreases during the entire horizon and housing decreases initially, but quickly becomes unclear.

Table 4: Contributions of MP and FP Regime Shocks (\%) to the Variance of Variables

\begin{tabular}{|c|c|c|c|}
\hline \multirow{2}{*}{ Variables } & \multicolumn{2}{|c|}{ Variance Decomposition } & \multirow{2}{*}{$R^{2}$} \\
\cline { 2 - 3 } & MP Regime Shocks & FP Regime Shocks & \\
\hline$w^{m}$ & 69.6 & 4.2 & $1^{*}$ \\
$w^{f}$ & 5.7 & 55.4 & $1^{*}$ \\
\hline GDP & 3.7 & 1.0 & 0.69 \\
Unemployment & 8.5 & 5.3 & 0.74 \\
Price Index & 13.5 & 4.1 & 0.53 \\
Total loans & 7.2 & 6.5 & 0.70 \\
Debt/GDP ratio & 31.7 & 1.5 & 0.78 \\
Int.payment/Govt.outlays ratio & 40.8 & 11.4 & 0.61 \\
10YTR & 29.5 & 8.8 & 0.86 \\
Housing Starts & 10.9 & 2.3 & 0.93 \\
\hline
\end{tabular}

Table 4 reports the forecast error variance decomposition results for the same macroeconomic 
variables considered in Figures 7-8. The second and third columns report the contributions of the monetary and fiscal policy regime shocks to the variance of the forecast errors of the common components at the 16 quarter horizons. ${ }^{29}$ The contribution of the shock to monetary regime factor has a huge effect on all variables, especially on debt to GDP ratio and net interest payment to government outlays ratio. The monetary regime shock accounts for $32 \%$ and $41 \%$ of the errors in the forecast of debt to GDP ratio and net interest payment to government outlays ratio that are closely related to fiscal policy stance. The monetary policy shock also has a nontrivial effect on fiscal regime factor itself, and explains 4\%,9\%, and 14\% of GDP, unemployment, and price index, respectively. The contributions of the shock to fiscal regime factor also has nontrivial effects, but smaller magnitudes, in explaining the errors in the forecasts of all variables we consider compared to those of the monetary policy shock.

Figure 9: Counterfactual IRFs of Policy Factors and Key Macro Variables to MP Regime Shock
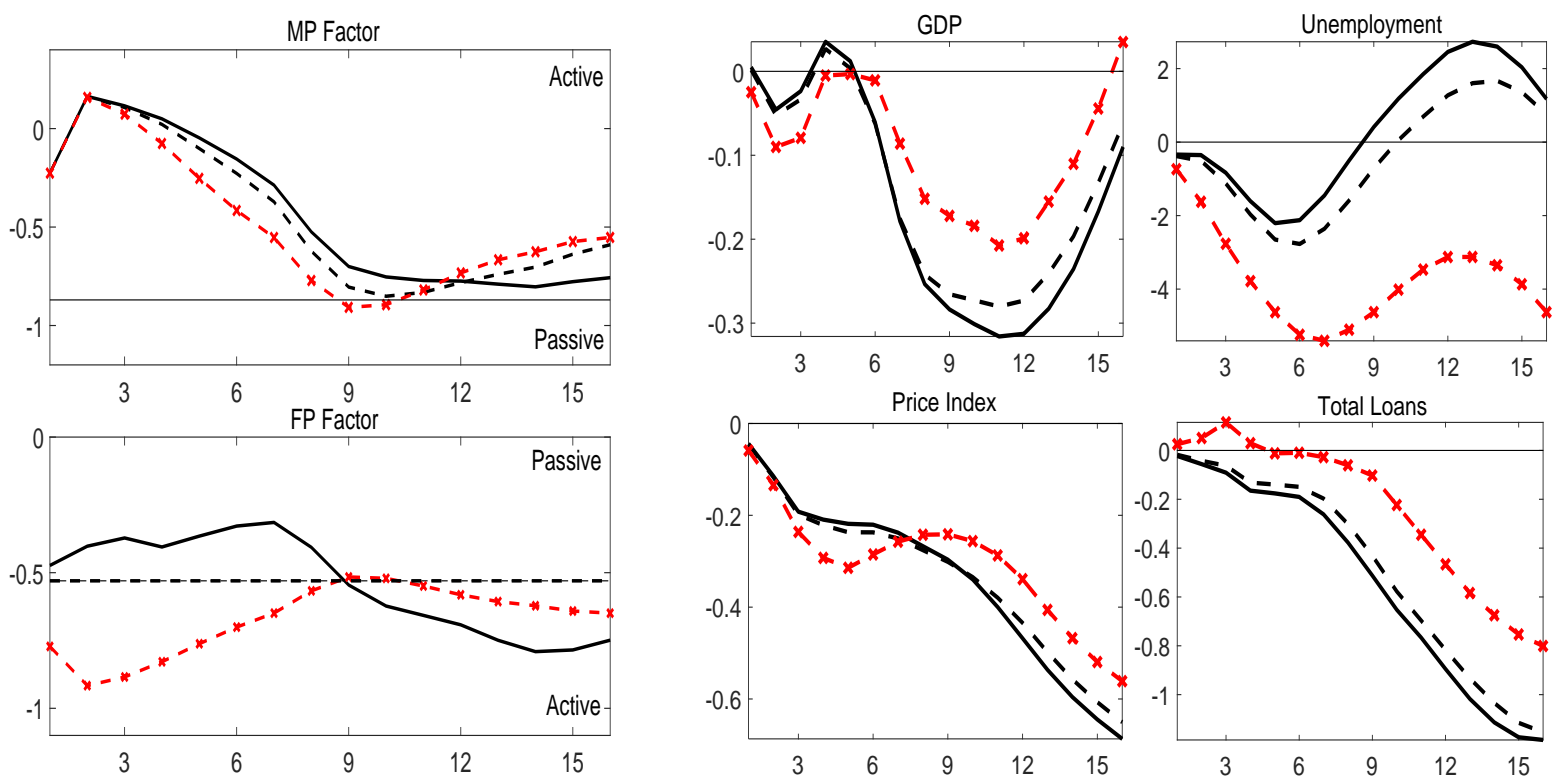

Thus far, we have scrutinized the effects of policy regime shocks to various macro variables. Now we conduct an interesting counterfactual analysis where we consider an alternative scenario where fiscal policy authority either does not respond to the change in monetary policy regime or does respond, but in the opposite direction to the original impulse responses to keep her own policy stance. In this counterfactual exercise, we consider the series of unanticipated and moderate fiscal policy regime shocks that either interrupts the fiscal policy response or induces it to respond in the opposite direction in order to offset the effect of the given active monetary policy regime shock. Figure 9 plots three impulse response functions of the fiscal policy factor to the given

\footnotetext{
${ }^{29}$ We follow the variance decomposition suggested by Bernanke et al. (2005) in FAVAR context. The relative importance of a structural shock is assessed relative only to the portion of the variable explained by the common factors. $R^{2}$ in Table 4 refers to the fraction of the variance of the variable explained by the common components. See Bernanke et al. (2005) for details.
} 
Figure 10: Counterfactual IRFs of Policy Factors and Key Macro Variables to FP Regime Shock
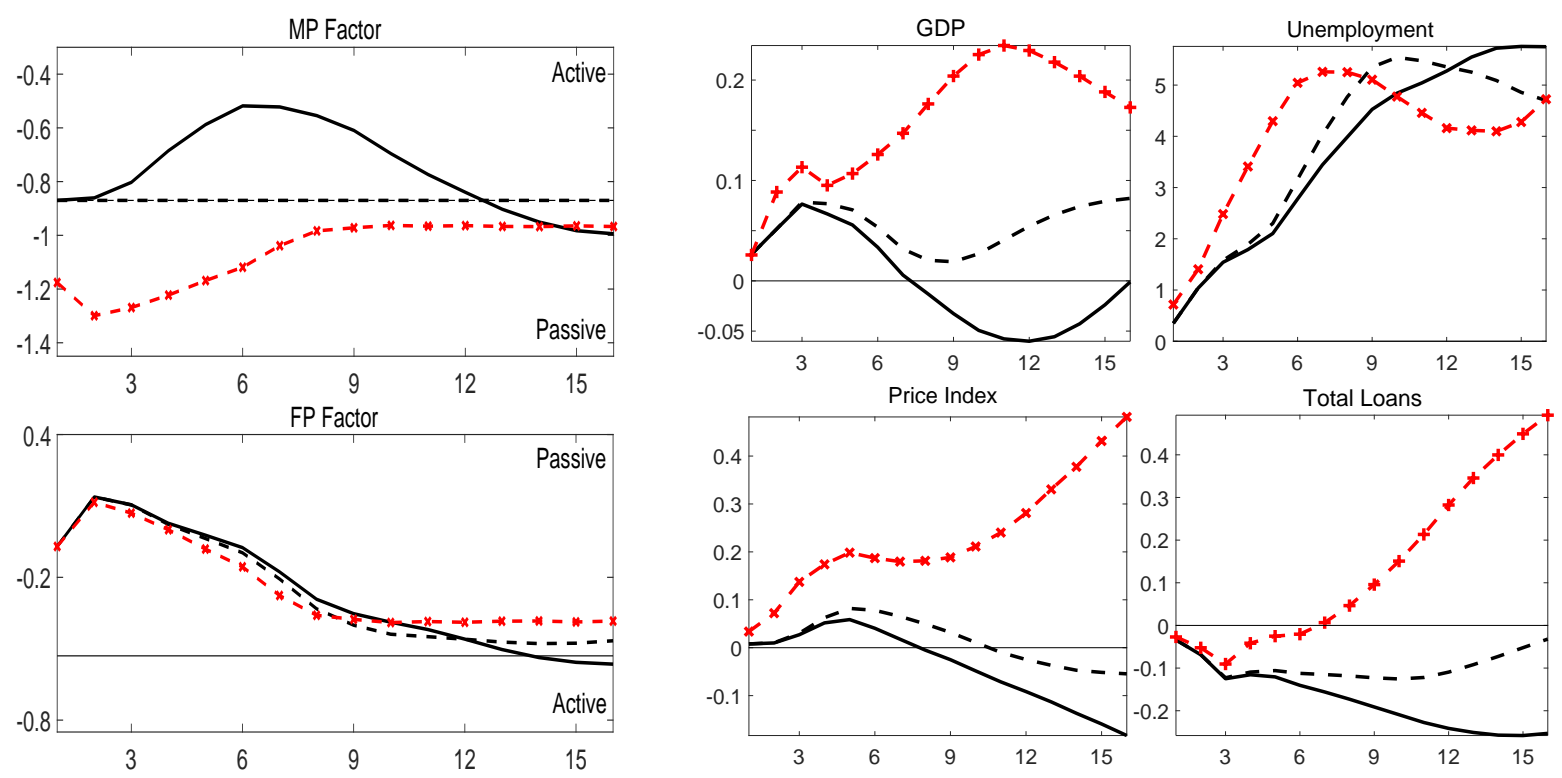

active monetary policy regime shock. The original response function is signified by solid line, the counterfactual response function obtained when fiscal policy does not respond by a blackdashed line, and the counterfactual response when fiscal policy responds in the opposite way with a red-star-dashed line. When the fiscal policy strongly holds on to its own policy stance and does not respond to the change in monetary policy regime, the probability of the monetary policy staying in active regime in the next period will decrease. The impulse responses of price level becomes slightly smaller than the original after 8 quarters with these counterfactual fiscal policy responses. In both alternate scenarios, GDP decreases, but overall less than the original response, and the impulse response of unemployment lie below the original response. In particular, when the fiscal policy responds in the opposite way and becomes more active along with the more active monetary policy, GDP decreases substantially less than the original response after 6 quarters. The unemployment decreases drastically, and the price level decreases but less than the original response after 7 quarters. Even if the monetary authority intends to change the policy regime more actively in order to control high inflation, the effect of the monetary policy regime change seems to vary depending on the fiscal authority's reaction.

Similarly, in Figure 10, we consider the scenario where the monetary policy authority does not respond to the change in fiscal policy regime or does respond in the opposite direction to the original impulse responses. Here, we observe more dramatic changes in GDP and the price level. GDP increases during the entire horizon without any decrease. The price level continues to increase in contrast to the original response. 


\section{Robustness Check}

\subsection{Stochastic Volatility}

All of our previous results are based on the endogenous regime switching model with a constant volatility. It has been emphasized by many authors, including Sims and Zha (2006), that the presence of time-varying volatility or stochastic volatility may have serious deleterious effects on the empirical analysis of policy rules using U.S. macro time series. ${ }^{30}$ In this section, we allow for the presence of general stochastic volatility in our model and consider a more general endogenous regime switching model to see how our previous results change.

To explain how we deal with the presence of a general form of stochastic volatility, we write our regime switching model (1) extended to allow for the presence of stochastic volatility generically as

$$
u_{t}=\sigma_{t} \varepsilon_{t}
$$

where $\sigma_{t}$ is a general time-varying and stochastic volatility, and $\varepsilon_{t} \sim \operatorname{iid} \mathbb{N}(0,1)$ independent of $\sigma_{t}$. Our approach to deal with the presence of stochastic volatility $\sigma_{t}$ in the error term consists of two steps: estimation of $\sigma_{t}$ in the first step ignoring the presence of stochastic volatility, and reestimation of the model in the second step using the standardized regressand and regressors. Analogous to with the feasible generalized least squares (GLS) correction for the usual OLS regression, our procedure relies on the feasible heteroskedasticity correction for the presence of stochastic volatility in our maximum likelihood estimation (MLE). Note that, if $\varepsilon_{t}$ is observed, $\sigma_{t}^{2}$ can be estimated from $u_{t}^{2}=\sigma_{t}^{2} \varepsilon_{t}^{2}=\sigma_{t}^{2}+\sigma_{t}^{2}\left(\varepsilon_{t}^{2}-1\right)$, where $1-u_{t}^{2}$ is i.i.d. with mean zero and independent of $\sigma_{t}^{2}$.

In the first step, we obtain the fitted residual under the constant volatility specification

$$
\hat{u}_{t}=y_{t}-x_{t}^{\prime} \hat{\beta}_{s_{t}}
$$

where $\hat{\beta}_{s_{t}}$ is the estimate based on our model with a constant volatility, and use $\hat{u}_{t}^{2}$ to estimate $\sigma_{t}^{2}$ using the Hodrick-Prescott (HP) filter with an appropriately chosen smoothing parameter. ${ }^{31}$ Subsequently, in the second step, we estimate the model

$$
y_{t}^{*}=x_{t}^{* \prime} \hat{\beta}_{s t}+u_{t}^{*}
$$

where $y_{t}^{*}$ and $x_{t}^{*}$ are volatility adjusted $y_{t}$ and $x_{t}$, given respectively by $y_{t}^{*}=y_{t} / \hat{\sigma}_{t}$ and $x_{t}^{*}=x_{t} / \hat{\sigma}_{t}$

\footnotetext{
${ }^{30}$ However, the actual specification of time varying or stochastic volatility varies widely in their work.

${ }^{31}$ If we let the smoothing parameter be $\lambda$ and denote by $H P\left(\varepsilon_{t}^{2}\right)$ the HP filtered series of $\varepsilon_{t}^{2}$, then the smoothing parameter we use here is given by

$$
\hat{\lambda}=\underset{\lambda}{\operatorname{argmin}} \sum_{t=1}^{T-1}\left|\left(\varepsilon_{t}^{2}-H P_{\lambda}\left(\varepsilon_{t}^{2}\right)\right)\left(\varepsilon_{t-1}^{2}-H P_{\lambda}\left(\varepsilon_{t-1}^{2}\right)\right)\right| .
$$

The reader is referred to Chang et al. (2016) for a more detailed discussion of this approach to nonparametrically estimate the conditional mean of a given time series.
} 
with the estimate $\hat{\sigma}_{t}$ of $\sigma_{t}$ obtained in the first step. Figure 13 in the Appendix presents estimated stochastic volatilities from monetary and fiscal policy rules.

To fully justify our procedure is difficult, and it certainly goes beyond the scope of this paper. We have two reasons why our procedure may not be entirely valid. First, for the validity of our procedure, we require that the fitted residual $\hat{u}_{t}$ should consistently estimate the true residual $u_{t}$ even if we ignore the presence of stochastic volatility. Clearly, this is generally not warranted for nonlinear models estimated by the MLE as in our case. Second, volatility adjustment of $y_{t}$ and $x_{t}$ using the estimated $\hat{\sigma}_{t}$ may not behave well enough to give us what we wish to have. For instance, it may create nonnegligible cross correlation between $x_{t}^{*}$ and $u_{t}^{*}$, in which case our procedure becomes totally invalid.

Table 5: Estimation Results for Volatility Adjusted Endogenous Regime Switching Policy Models

\begin{tabular}{c|cc||c|cc}
\hline \multicolumn{3}{c||}{ Monetary Policy Rule } & \multicolumn{3}{c}{ Fiscal Policy Rule } \\
\hline Parameter & Estimate & S.E & Parameter & Estimate & S.E \\
\hline$\alpha_{m}$ & 0.989 & $(0.006)$ & $\alpha_{f}$ & 0.960 & $(0.021)$ \\
$\psi_{m}$ & -0.848 & $(2.436)$ & $\psi_{f}$ & -1.032 & $(0.976)$ \\
$\rho_{m}$ & 0.993 & $(0.060)$ & $\rho_{f}$ & 0.972 & $(0.038)$ \\
\hline$a_{c}\left(s_{t}^{m}=0\right)$ & 0.615 & $(0.141)$ & $\beta_{c}\left(s_{t}^{f}=0\right)$ & -0.021 & $(0.004)$ \\
$a_{c}\left(s_{t}^{m}=1\right)$ & 2.133 & $(0.134)$ & $\beta_{c}\left(s_{t}^{f}=1\right)$ & 0.008 & $(0.003)$ \\
$a_{\pi}\left(s_{t}^{m}=0\right)$ & 0.649 & $(0.045)$ & $\beta_{b}\left(s_{t}^{f}=0\right)$ & -0.017 & $(0.007)$ \\
$a_{\pi}\left(s_{t}^{m}=1\right)$ & 1.067 & $(0.051)$ & $\beta_{b}\left(s_{t}^{f}=1\right)$ & 0.048 & $(0.007)$ \\
& & & $\beta_{g}\left(s_{t}^{f}=0\right)$ & 0.960 & $(0.035)$ \\
& & & $\beta_{g}\left(s_{t}^{f}=1\right)$ & 0.658 & $(0.025)$ \\
\hline
\end{tabular}

Nevertheless, if our procedure is valid, then we may expect that the new estimates are close to our previous estimates with smaller standard errors. Fortunately, this is exactly what we have, and we may argue the validity of our procedure in this sense. We see this as a positive sign that our two step procedure to deal with the presence of stochastic volatility works properly at least for our model. The new results are presented in Table 5. As shown, there are only minor differences between the estimates from our original model and those from the model with stochastic volatility obtained using the two step procedure. In contrast, the standard errors of the estimates are substantially reduced, as we expect. Most of standard errors of the estimates are reduced by more than $30 \%$, with some of them by as much as $50 \% .^{32}$

\subsection{Zero Lower Bound}

Since December 2008, the FFR has been near zero, and the central bank cannot stimulate the economy by lowering the interest rate further. During the zero lower bound (ZLB) period, central banks rely on unconventional policy instruments such as quantitative easing and forward guidance to try to affect long-term interest rates and influence the economy. The structural change in terms

\footnotetext{
${ }^{32}$ We also obtain $\hat{\sigma}_{t}$ using GARCH $(1,1)$ or endogenous regime switching volatility model, and estimate the models with volatility adjusted $y_{t}$ and $x_{t}$. Overall, the estimates are not sensitive to volatility model and estimation method used to deal with the presence of volatility.
} 
of the effectiveness of the FFR as a policy instrument raises questions on how we should sensibly deal with the data covering the ZLB period.

Two different approaches have been suggested to handle the issues related to the ZLB of interest rates. The first approach is to simply discard the ZLB period and use a truncated data series up to 2008:4, while the second approach is to handle the ZLB period using shadow rates such as those provided by Wu and Xia (2016), which may convey a further information about policy behaviors during the ZLB period. Since analyzing policy interactions after the financial crisis is one of our key interests, we take the second approach and use the estimated shadow rates from Wu and Xia (2016) to construct a new policy rate $i_{t}^{*}$ by splicing together T-bill rate $i_{t}$ until $t=2008: 4$ and the estimated shadow rate $\hat{i}_{t}$ from $t=2009: 1$.

Figure 14 provided in the Appendix compares the two monetary policy factors: the original factor we presented earlier, which is extracted using the original T-bill rate $i_{t}$, and the new factor extracted using the new policy rate $i_{t}^{*}$. Overall, the regimes identified by the two factors are identical, except for a short period in the early 1960s. This period is identified as a passive regime by the original factor, but contrastingly as an active regime by the new factor. The magnitudes of the factors are also similar overall, but the new factor becomes smaller than the original factor since 2010:1. This means that the new monetary policy factor obtained from $i_{t}^{*}$ sends a stronger signal that monetary policy will be passive in the next period compared to what is predicted by the original monetary policy factor. This may imply that the shadow rate embedded in the new policy rate $i^{*}$ brings in more information relevant to the policy making such as that conveyed in the forward guidance quotes which are related to a different lift-off date or condition for the ZLB announced by the Fed. For an example, consider the quote announced on 6/19/2013 during the press conference by the former Chairman Bernanke. ${ }^{33}$ Such a forward guidance quote may influence market participants to expect a delay in the lift-off date of the ZLB and consequently a continuation of the passive monetary policy regime in the future periods. It can be seen clearly that the new monetary policy factor starts to decrease in 2013:3 after the 6/19/2013 announcement, which may be due to the market's updated expectation that the central bank may keep the current passive policy stance at least for the next several periods.

Figure 15 in the Appendix presents the time varying policy interactions obtained from TVCVAR analysis implemented with the new monetary policy factor based on the new policy rate $i_{t}^{*}$ and the fiscal regime factor. ${ }^{34}$ Again we observe similar patterns of time varying policy interactions in terms of both magnitudes and signs compared to those obtained from our earlier TVC-VAR analysis implemented with the original monetary factor based on $i_{t}$.

\footnotetext{
${ }^{33}$ The quote states "...14 of 19 FOMC participants indicated that they expect the first increase in the target for the federal funds rate to occur in 2015 , and one expected the first increase to incur in 2016."

${ }^{34}$ We follow the same specification for TVC-VAR estimation considered in Section 3.
} 


\section{Conclusion}

Monetary and fiscal regimes display strong dynamic interactions in postwar U.S. data. Estimating the endogenous nature of the evolution of policy regimes is essential to this conclusion: it points research toward understanding how the central bank's choice of monetary rule influences the government's choice of fiscal rule and vice versa. Modeling regime change as endogenous also sheds light on how macroeconomic developments affect systematic policy behavior.

Three key findings emerge. First, estimated policy coefficient imply that monetary and fiscal policy behavior fluctuates between two theoretically interpretable regimes and that changes in one policy rule help to predict changes in the other policy rule. Second, government debt, the term structure of interest rates, and other macroeconomic variables exhibit strong dynamic correlations with estimated policy regime factors. Third, shocks to non-policy variables, particularly those associated with real economic activity, generate movements in policy regimes.

These findings suggest both that the econometric techniques that Chang et al. (2017) develop can uncover potentially important policy interactions and that those interactions bear more thorough economic analysis. The next step is to integrate the econometric methods with a fully-specified dynamic stochastic general equilibrium model. In such a model, the estimated latent factors may reflect agents' time-varying beliefs about the prevailing policy regime. As beliefs evolve over time, so too will agents' rules for decision. Integration of the econometrics with the economic theory would permit joint estimation of the parameters associated with the endogenous switching process and with economic behavior. 


\section{References}

Aiyagari, R., Gertler, M., 1985. The Backing of Government Bonds and Monetarism. Journal of Monetary Economics 16 (1), 19-44.

Auerbach, A. J., 2003. Fiscal Policy, Past and Present. Brookings Papers on Economic Activity (1), 75-122.

Ballabriga, F. C., Martinez-Mongay, C., 2005. Sustainability of EU Public Finances. European Commission Economic Papers 225.

Barthélemy, J., Marx, M., 2017. Solving Endogenous Regime Switching Models. Journal of Economic Dynamics and Control 77, 1-25.

Bernanke, B., Boivin, J., Eliasz, P. S., 2005. Measuring the Effects of Monetary Policy: A Factoraugmented Vector Autoregressive (FAVAR) Approach. The Quarterly Journal of Economics $120(1), 387-422$.

Bianchi, F., Ilut, C., 2017. Monetary/Fiscal Policy Mix and Agent's Beliefs. Review of Economic Dynamics 26, 113-139.

Board of Governors of the Federal Reserve System, 1993. Transcript of Federal Open Market Committee, (March 23).

Bohn, H., 1998. The Behavior of U.S. Public Debt and Deficits. The Quarterly Journal of Economics 113, 949-963.

Chang, Y., Choi, Y., Park, J. Y., 2017. A New Approach to Model Regime Switching. Journal of Econometrics 196 (1), 127-143.

Chang, Y., Park, J. Y., Yeo, H., 2016. Using Hodrick-Prescott Filter to Nonparametrically Estimate Conditional Mean Process. Working paper, Indiana University.

Claeys, P., 2004. Monetary and Budgetary Policy Interaction: An SVAR Analysis of Stabilization Policies in Monetary Union. Working paper, European University Institute.

Clarida, R., Gali, J., Gertler, M., 2000. Monetary Policy Rules and Macroeconomic Stability: Evidence and Some Theory. The Quarterly Journal of Economics 115, 147-180.

Cogley, T., Sargent, T. J., 2005. Drifts and Volatilities: Monetary Policies and Outcomes in the Post WWII U.S. Review of Economic Dynamics 8 (2), 262-302.

Cohen, D. S., Follette, G. R., 2005. Forecasting Exogenous Fiscal Variables in the United States. Fianace and Economics Discussion Series 2003-59, Federal Reserve Board. 
Davig, T., 2004. Regime-Switching Debt and Taxation. Journal of Monetary Economics 51 (4), 837-859.

Davig, T., Leeper, E. M., 2006a. Endogenous Monetary Policy Regime Change. In: Reichlin, L. and West, K.D. (Ed.), NBER International Seminar on Macroeconomics 2006. University of Chicago Press, Chicago, IL, pp. 345-391.

Davig, T., Leeper, E. M., 2006b. Fluctuating Macro Policies and the Fiscal Theory. In: Acemoglu, D., Rogoff, K. and Woodford, M. (Ed.), NBER Macroeconomics Annual 2006, Volume 21. MIT Press, Cambridge, MA, pp. 247-316.

Davig, T., Leeper, E. M., Chung, H., 2004. Monetary and Fiscal Policy Switching. Working Paper 10362, National Bureau of Economic Research.

Efron, B., Hastie, T., Johnstone, I., Tibshirani, R., 2004. Least Angle Regression. The Annals of Statistics 32 (2), 407-499.

Fan, J., Li, R., 2001. Variable Selection via Nonconcave Penalized Likelihood and Its Oracle Properties. Journal of the American Statistical Association 96 (456), 1348-1360.

Fatas, A., Mihov, I., 2001. Politica Fiscal y Ciclos Economicos: Una Investigacion Empirica (Fiscal Policy and the Business Cycle: An Empirical Analysis). Moneda y Credito 212, 167-210.

Favero, C. A., Monacelli, T., 2005. Fiscal Policy Rules and Regime (In)Stability: Evidence from the U.S. Working Paper 282, IGIER.

Gali, J., Gambetti, L., 2009. On the Sources of the Great Moderation. American Economic Journal: Macroeconomics 1 (1), 26-57.

Giraitis, L., Kapetanios, G., Yates, T., 2014. Inference on Stochastic Time-Varying Coefficient Models. Journal of Econometrics 179 (1), 46-65.

Giraitis, L., Kapetanios, G., Yates, T., 2015. Inference on Multivariate Heteroscedastic Time Varying Random Coefficient Models. Working Papers 767, Queen Mary University of London.

Gonzalez-Astudillo, M., 2013. Monetary-Fiscal Policy Interactions: Interdependent Policy Rule Coefficients. Finance and Economics Discussion Series 2013-58, Board of Governors of the Federal Reserve System.

Ireland, P. N., 2004. Money's Role in the Monetary Business Cycle. Journal of Money, Credit and Banking 36 (6), 969-983.

Kilian, L., 1998. Small-Sample Confidence Intervals For Impulse Response Functions. The Review of Economics and Statistics 80, 218-230. 
King, M., 1995. Commentary: Monetary Policy Implications of Greater Fiscal Discipline. In: Budget Deficits and Debt: Issues and Options. Federal Reserve Bank of Kansas City Economic Conference Proceedings, Jackson Hole Symposium, pp. 171-183.

King, R. G., Plosser, C. I., 1985. Money, Deficits, and Inflation. Carnegie-Rochester Conference Series on Public Policy 22 (1), 147-195.

Kliem, M., Kriwoluzky, A., Sarferaz, S., 2016. On the Low-Frequency Relationship Between Public Deficits and Inflation. Journal of Applied Econometrics 31 (3), 566-583.

Koop, G., Korobilis, D., 2010. Bayesian Multivariate Time Series Methods for Empirical Macroeconomics. Foundations and Trends in Econometrics 3 (4), 267-358.

Kozicki, S., 2004. How Do Data Revisions Affect the Evaluation and Conduct of Monetary Policy? Economic Review (Q I), 5-38.

Leeper, E. M., 1991. Equilibria Under 'Active' and 'Passive' Monetary and Fiscal Policies. Journal of Monetary Economics 27 (1), 129-147.

Leeper, E. M., Roush, J. E., 2003. Putting 'M' Back in Monetary Policy. Journal of Money, Credit and Banking 35 (6), 1217-1256.

Melitz, J., 1997. Some Cross-Country Evidence about Debt, Deficits and the Behaviour of Monetary and Fiscal Authorities. CEPR Discussion Paper 1653.

Melitz, J., 2000. Some Cross-Country Evidence about Fiscal Policy Behavior and Consequences for EMU. Unpublished Manuscript.

Muscatelli, A., Tirelli, P., Trecroci, C., 2002. Monetary and Fiscal Policy Interactions over the Cycle: Some Empirical Evidence. CESifo Working Paper Series 817, CESifo Group Munich.

Ohanian, L. E., 1997. The Macroeconomic Effects of War Finance in the United States: World War II and the Korean War. American Economic Review 87 (1), 23-40.

Pechman, J., 1987. Federal Tax Policy. Fifth Ed. The Brookings Institution, Washington, D.C. .

Poterba, J., 1994. Federal Budget Policy in the 1980s. In: Feldstein, M. (Ed.), American Economic Policy in the 1980s, University of Chicago Press, Chicago, IL. MIT Press, Cambridge, MA, pp. 235-270.

Primiceri, G. E., 2005. Time Varying Structural Vector Autoregressions and Monetary Policy. Review of Economic Studies 72, 821-852.

Romer, C. D., Romer, D. H., 2002. A Rehabilitation of Monetary Policy in the 1950's. American Economic Review 92 (2), 121-127. 
Romer, C. D., Romer, D. H., 2004. Choosing the Federal Reserve Chair: Lessons from History. Journal of Economic Perspectives 18 (1), 129-162.

Rosset, S., Zhu, J., 2007. Piecewise Linear Regularized Solution Paths. The Annals of Statistics $35(3), 1012-1030$.

Rotemberg, J. J., Woodford, M., 1999. Interest Rate Rules in an Estimated Sticky Price Model. In: Taylor, J.B. (Ed.), Monetary Policy Rules. University of Chicago Press, Chicago, IL, pp. 57-126.

Sargent, T. J., Wallace, N., 1981. Some Unpleasant Monetarist Arithmetic. Quarterly Review (Fall).

Sims, C. A., 1988. Identifying Policy Effects. In: Bryant, R.C. et al (Ed.), Empirical Macroeconomics for Interdependent Economics. The Brookings Institution, Washington, D.C., pp. 308 321.

Sims, C. A., Zha, T., 2006. Were There Regime Switches in U.S. Monetary Policy? American Economic Review 96 (1), 54-81.

Stein, H., 1996. In: The Fiscal Revolution in America. Second Revised Ed. AEI Press, Washington, D.C.

Steuerle, C., 2002. Tax Policy from 1990 to 2001. In: J. Frankel, and Orszag, P. (Ed.), American Economic Policy in the 1990s, MIT Press, Cambridge, MA. pp. 139-169.

Stone, M., 1974. Cross-Validatory Choice and Assessment of Statistical Predictions. Journal of the Royal Statistical Society. Series B (Methodological) 36 (2), 111-147.

Taylor, J. B., 1993. Discretion versus Policy Rules in Practice. Carnegie-Rochester Conference Series on Public Policy 39 (1), 195-214.

Taylor, J. B., 2000. Reassessing Discretionary Fiscal Policy. Journal of Economic Perspectives $14(3), 21-36$.

Tibshirani, R., 1996. Regression Shrinkage and Selection Via the Lasso. Journal of the Royal Statistical Society, Series B 58, 267-288.

Unsigned, 2005a. Still Gushing Forth. The Economist, (February 3) .

Unsigned, 2005b. Saturated. The Economist, (February 24) .

von Jagen, J., Hallett, A. H., Strauch, R., 2001. Budgetary Consolidation in EMU. Economic Papers 148, European Commission Brussels.

Wallace, N., 1981. A Modigliani-Miller Theorem for Open-Market Operations. The American Economic Review 71 (3), 267-274. 
Woodford, M., 2001. Fiscal Requirements for Price Stability. Journal of Money, Credit and Banking $33,669-728$.

Wu, J. C., Xia, F. D., 2016. Measuring the Macroeconomic Impact of Monetary Policy at the Zero Lower Bound. Journal of Money, Credit, and Banking 48 (2-3), 253-291.

Yang, S.-C. S., 2007. Tentative Evidence of Tax Foresight. Economics Letters 96 (1), 30-37.

Zou, H., 2006. The Adaptive Lasso and Its Oracle Properties. Journal of the American Statistical Association 101, 1418-1429. 


\section{Appendix}

\section{Appendix A: Additional Tables and Figures}

Table 6: Implied Averages of Variables Conditional on Regime

\begin{tabular}{c||c|c|c|c|c}
\hline Regime & T-bill rate & Inflation rate & Tax/GDP & Debt/GDP & Govt.Spending/GDP \\
\hline Active & 6.11 & 3.39 & 0.06 & 0.38 & 0.10 \\
Passive & 2.43 & 3.01 & 0.10 & 0.33 & 0.11 \\
\hline
\end{tabular}

Notes: Table 6 reports the implied averages of variables used in estimations of MP and FP rules conditional on regime. Average inflation, debt/GDP and government spending ratios are calculated from actual data conditional on regime, and implied averages of interest rate and tax/GDP ratio are calculated by plugging those averaged variables by regime and regime dependent intercept terms into the policy rules.

Figure 11: IRFs of Policy Regime Shocks on Selected Years
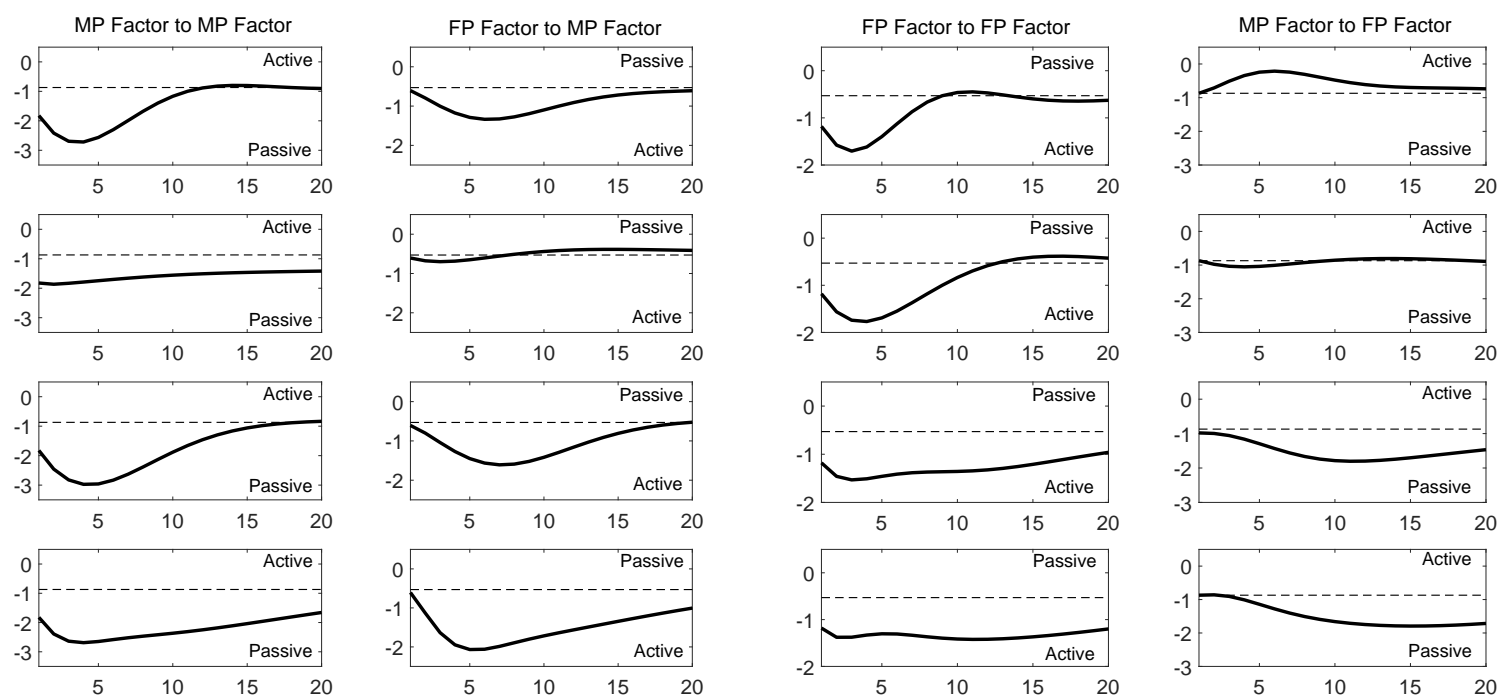

Notes: The four columns present IRFs of MP factor to MP regime shock, of FP factor to MP regime shock, of FP factor to FP regime shock and of MP factor to FP regime shock from left to right. Dotted straight line are estimated thresholds for monetary policy $(-0.87)$ or fiscal policy (-0.54) respectively. The $x$-axis represents quarters after the shock, the $y$-axis represents the value of the responses to a negative one standard deviation shock to policy regimes. For the first two columns, considered years are (the first quarter of) 1965, 1982, 2005, 2013 from top to bottom rows. For the last two columns, 1955, 1982, 2005, 2013 are considered. 
Figure 12: IRFs of Policy Regime Shocks on Selected Horizons
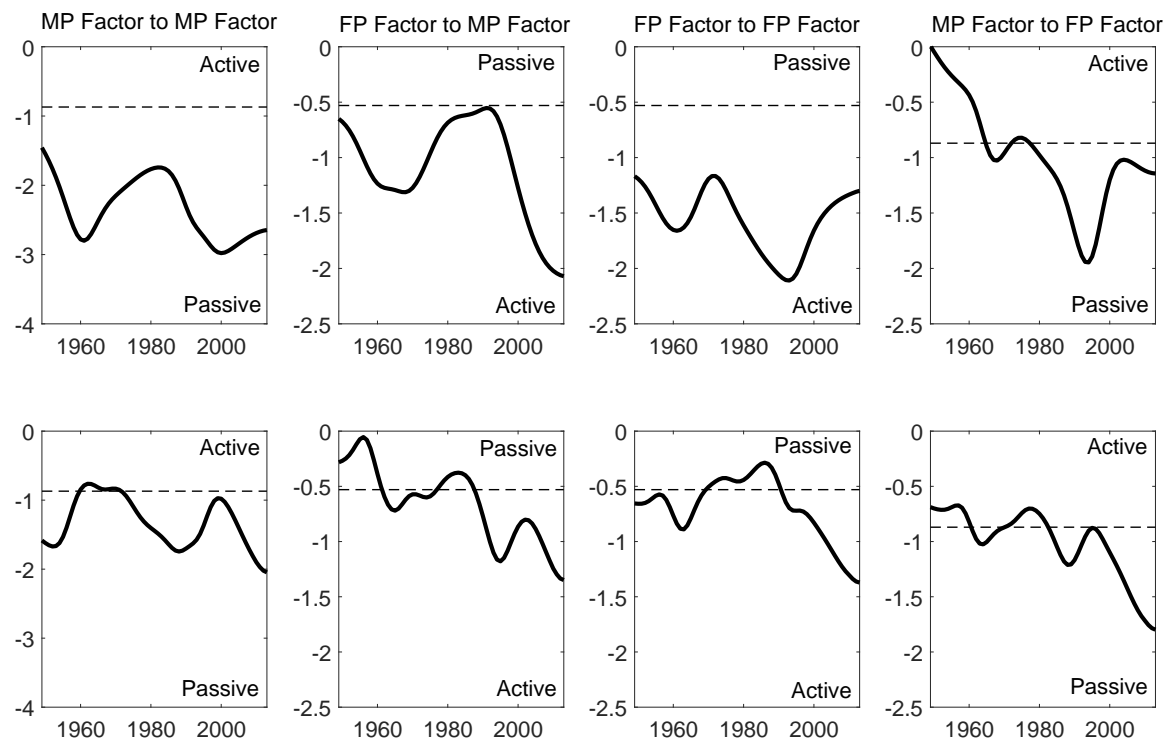

Notes: The four columns represent IRFs of MP factor to MP regime shock, of FP factor to MP regime shock, of FP factor to FP regime shock and of MP factor to FP regime shock from left to right. Dotted straight lines are estimated threshold levels of the responding policy factors. The $x$-axis represents the time periods of the initial policy regime shock. The $y$-axis represents the value of the response to a negative one standard deviation shock to policy factors. The first and second rows show the values of the responses after 5 and 15 quarters respectively from the initial shock.

Figure 13: Estimated Stochastic Volatility for Policy Rules
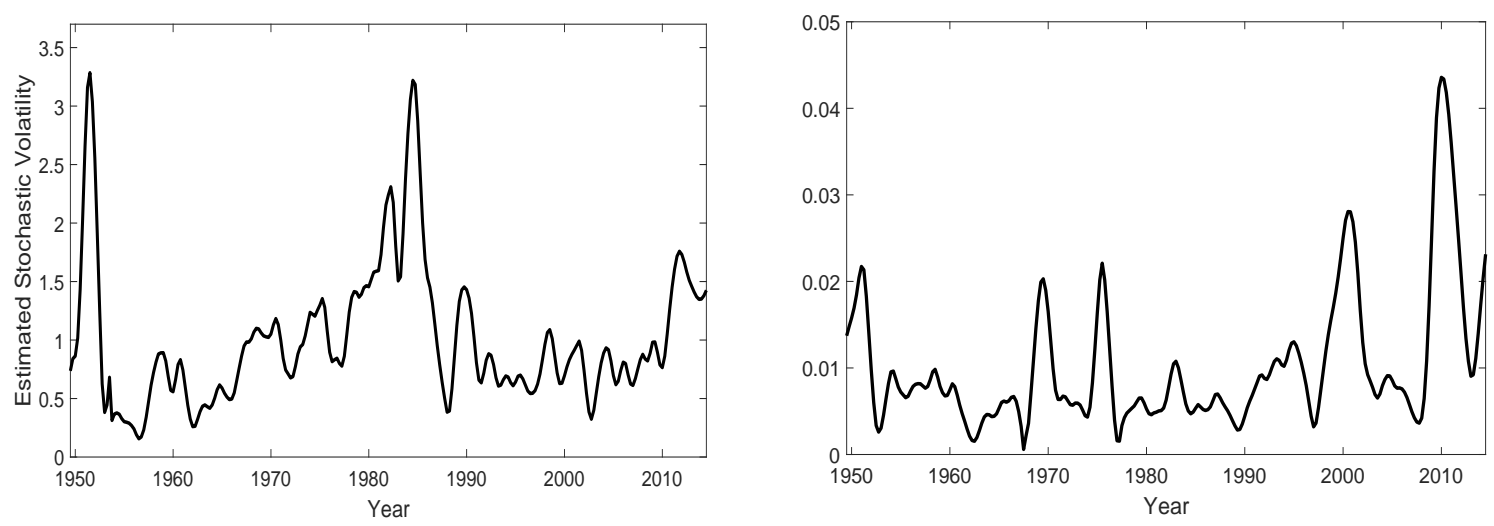

Notes: Figure 13 presents the estimated stochastic volatility for the monetary (the left) and fiscal (the right) policy rules. The stochastic volatility is estimated using a two-step approach and the HP filter with an appropriately chosen smoothing parameter. 
Figure 14: Extracted Monetary Factors from $i_{t}$ and $i_{t}^{*}$

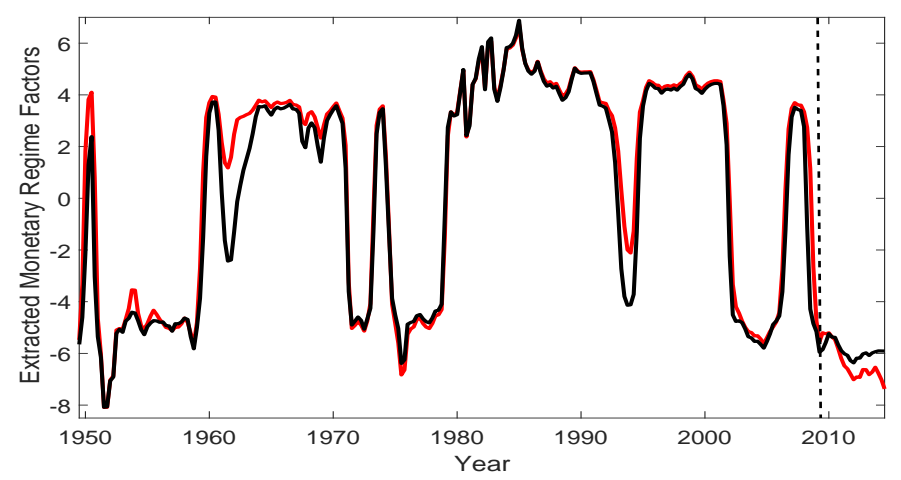

Notes: The black line is the extracted monetary regime factor using $i_{t}$ and the red line represents the extracted monetary policy factor using $i_{t}^{*}$ constructed as a combination of the T-bill rate and the estimated shadow rate by Wu and Xia (2016).

Figure 15: IRFs of Policy Factors to Policy Regime Shocks in TVC-VAR with Shadow Rate
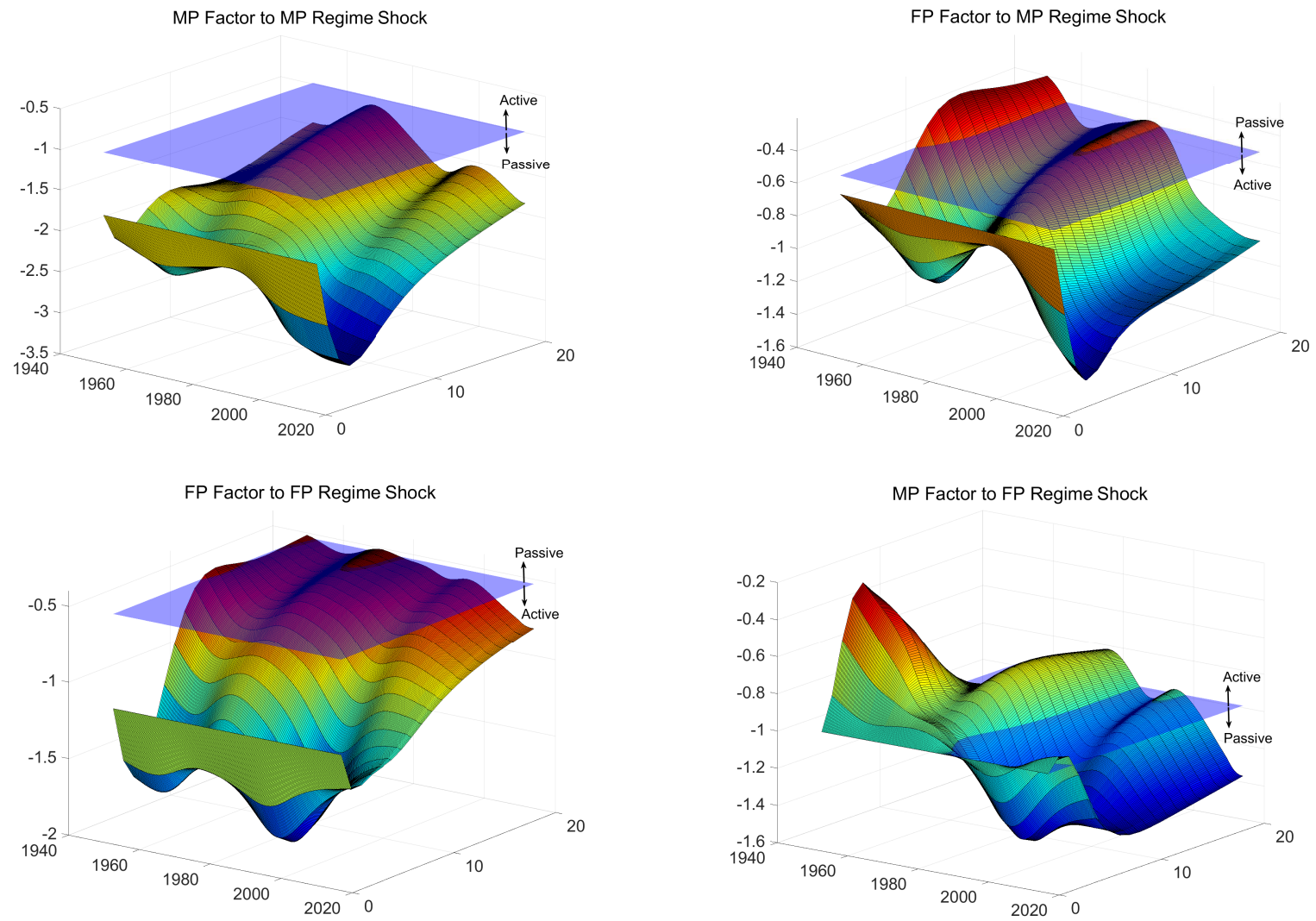

Notes: Monetary regime factor is re-estimated using a new policy rate $\left(i_{t}^{*}\right)$. Blue transparent surfaces represent the estimated thresholds for monetary and fiscal policy rules. The $x$-axis represents quarters after the shock, $y$-axis represents the time periods from 1949:2 to 2014:2 and $z$-axis is the value of the response of policy factors to a negative one standard deviation shock to monetary or fiscal regime factor respectively. 


\section{Appendix B: Endogenous and Conventional Regime Switching Models}

We compare estimates from our endogenous regime switching model with those from the conventional regime switching model in previous empirical studies. Mainly, we consider Davig and Leeper (2006b), which will be referred to as DL hereafter. DL estimate exogenous regime switching monetary and fiscal policy rules using U.S. data from 1948:2 to 2004:1. Their model includes output gap and heterogenous errors in their specification unlike ours, so it is hard to compare estimates directly. Except the 1960s, our estimated monetary policy regime is consistent with their estimated policy regimes. In our result, estimated monetary policy regime is active in 1962-1970 but estimates in DL imply that monetary policy is passive during that period. For the fiscal policy, our results are also similar to estimates in DL except the 1960s. Fiscal policy regime is passive in our endogenous regime switching estimates, but DL estimate this period as mainly active.

We also compare estimates from our endogenous regime switching model with those from the conventional regime switching model which is corresponding to our specification. If we found differences in estimated policy regime, there are two possible sources which generate differences. First, introducing endogeneity may induce a difference. Second, the different way of state identification can be a source of a difference. A state in our endogenous regime switching model is identified depending upon whether the extracted latent factor is greater than the estimated threshold whereas a state in the conventional regime switching model is identified depending upon whether the inferred probability is greater than 0.5 . However, the latter source may not generate the main difference in estimated policy regimes once filtered or smoothed probabilities are far from 0.5. Figure 16 presents comparisons between the estimated policy regimes from the endogenous regime switching policy rules and that from the conventional markov switching policy rules corresponding to our specification. In the case of monetary policy rule, estimated policy regimes from endogenous regime switching and conventional regime switching models are overlapped mainly with minor differences.

The estimated policy regimes for the fiscal policy, however, show more differences between endogenous regime switching and conventional regime switching estimations. As shown in the right-hand-side of Figure 16, the conventional regime switching model with our specification fails to capture some important fiscal events including Korean War in the 1950s, Clinton's tax hike in the 1990s and Bush tax cuts in the 2000s. Those differences mainly come from the introducing endogeneity in the model. ${ }^{35}$

The maximum log likelihood from the endogenous regime switching model is much higher than that from the corresponding exogenous regime switching model for MP and FP. Also, by comparing estimated policy regimes from our endogenous regime switching with the conventional Markov switching models under the same specification, we observe that estimates from endogenous regime switching model captures interpretable historical policy events more than the conventional Markov switching model. The endogenous switching model exploits the information from the past values of the observed time series to update the transition probability. Endogeneity in regime switching

\footnotetext{
${ }^{35}$ Different ways of state identification make minor differences in the fiscal policy rule.
} 
creates an important additional link between the latent states and observed time series. The information that can be channeled through this link cannot be exploited if we consider the exogenous regime switching model. We may need to consider other specifications of policy rule further for more clear comparison between our estimates and those from previous empirical studies including DL. However, this simple policy rule specification shows us how our endogenous regime switching model can work and give an inference about underlying policy regime.

Figure 16: Conventional Regime Switching Policy Models and Estimated Policy Regimes
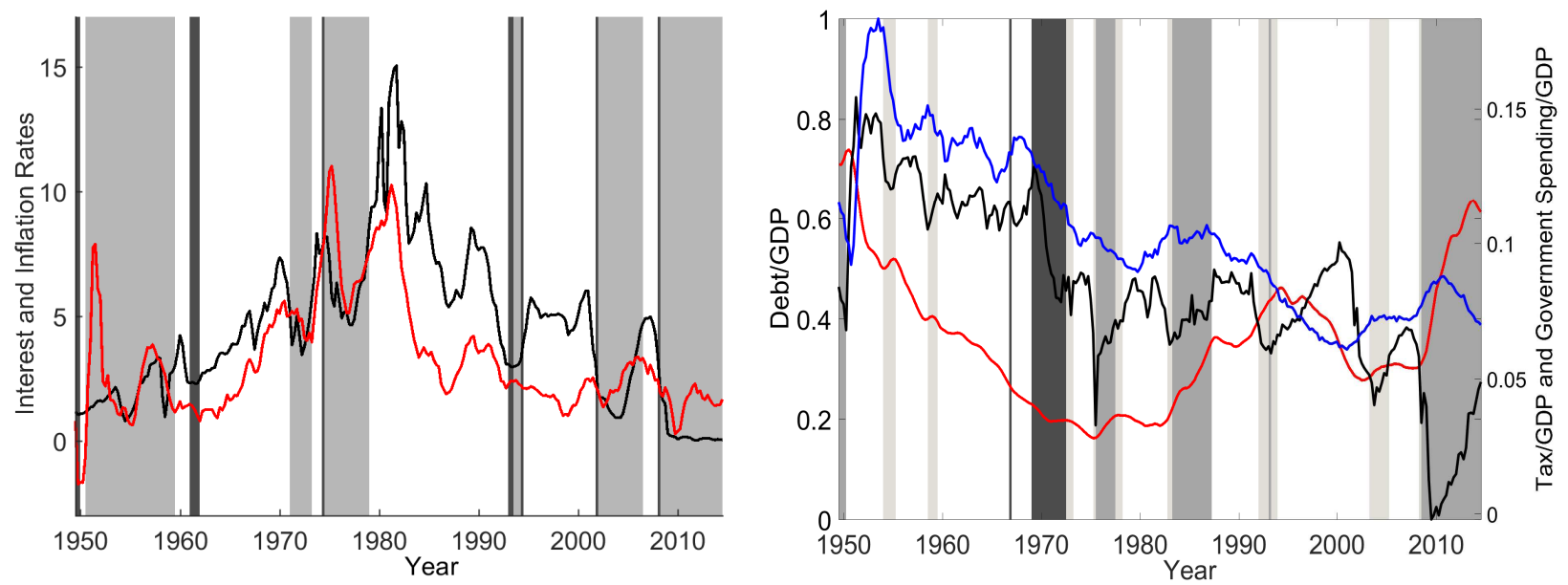

Notes: Figure 16 presents the comparison between the estimated policy regimes from the endogenous regime switching monetary and fiscal policy models and that from the conventional markov switching models corresponding to our specification. For the left panel of Figure 16, the light grey shade is the identified passive MP regime only for the endogenous regime switching model and the medium grey shade is the identified passive MP regime for both model. Dark grey shade represents the identified passive MP only for the conventional markov switching model. In the right panel of Figure 16, light grey shade is the identified active FP regime only for the endogenous regime switching model. Medium grey shade is the identified active FP regime for both models. Dark grey shade represents the identified active FP only for the conventional markov switching model. The endogenous regime switching model identifies a regime based on the policy regime factor and the estimated threshold, whereas the conventional markov switching model identifies a regime based on the inferred probability. 


\section{Appendix C: Fixed Coefficient VARs for Subsamples}

We consider a bivariate VAR with the monetary and fiscal regime factors to analyze the systematic interactions in policy rules. By considering possible policy implementation lags, we focus on the eighth order of VAR. ${ }^{36}$ For identification of the VAR, we employ a triangular scheme that fiscal regime factor is contemporaneously affected by monetary regime factor but not vice versa. In other words, monetary authority changes their policy stance first, and fiscal authority behaves later after they observe the monetary policy stance. We also analyze the time variations in the policy interaction via subsample analysis. Here we consider two sample periods, full sample period (1949:2-2014:2) and subsample period (2000:2-2014:2) respectively. Our VAR analysis for the full sample period may give an averaged relationship between two policy authorities during last 65 years. In the subsample analysis, we mainly consider the periods that have been asserted as the periods with passive monetary and active fiscal policy combination. For the full sample period, average of monetary regime factor is 0.71 (active) and average of fiscal regime factor is -0.28 (passive). The subsample period, in contrast, average of monetary regime factor is -1.24 (passive) and average of fiscal regime factor is -3.79 (active) given thresholds.

Based on the estimated VAR(8), we analyze the impulse responses. For each policy, we add one negative standard deviation shock from the estimated thresholds. ${ }^{37}$ Note that the level information about the latent factors is important in the determination of each regime given thresholds. For the shock on a policy regime, we observe that the other policy regime is changed in the direction which is consistent with a theoretical prediction of price level determination. For instance, if MP regime becomes passive with a shock in monetary policy regime, fiscal regime factor decreases and fiscal policy becomes active.

The left panel of Figure 17 shows impulse response functions of $\operatorname{VAR}(8)$ with $90 \%$ confidence interval error bands for the full sample period. When FP regime becomes active with a shock in fiscal regime, monetary policy becomes passive. However, the response of monetary policy regime to the change in fiscal regime is a little unclear with wider error band and small magnitude. Under the $5 \%$ significant level, Granger causality test rejects the null hypothesis that monetary policy factor does not Granger cause fiscal policy factor and cannot reject the null that fiscal policy factor does not Granger cause monetary policy factor.

The right panel of Figure 17 presents impulse response functions of $\operatorname{VAR}(8)$ for the subsample period. According to impulse response functions, monetary and fiscal authorities seem to respond to each others' regime switching clearer, especially for the response of monetary policy regime to shock to fiscal regime. In contrast to full sample period analysis, Granger causality test rejects the null hypothesis that fiscal policy factor does not Granger cause monetary policy factor and reject the null that monetary policy factor does not Granger cause fiscal policy factor under the

\footnotetext{
${ }^{36}$ We consider VARs with various lags, and we find that the estimation results are quite stable for VAR(r) with $r \geq 5$.

${ }^{37}$ Our impulse response function starts from estimated thresholds for a convenient description of the direction and magnitude of responses.
} 
$5 \%$ significant level.

We observe that when monetary policy regime becomes more active, fiscal policy regime tends to be more passive and vice versa in both sample period. Also, we find the time-varying interactions between two policy authorities by comparing the full sample and the subsample periods. Especially, monetary policy regime responds weakly to a change in fiscal policy regime in the full sample period, whereas in the subsample period, monetary policy regime responds strongly to a change in fiscal policy regime with the large response and narrow error band. Overall, the policy interaction between MP and FP tends to be stronger and clearer during the subsample period.

Figure 17: IRFs of Policy Factors to Policy Regime Shocks in Full and Subsample Periods
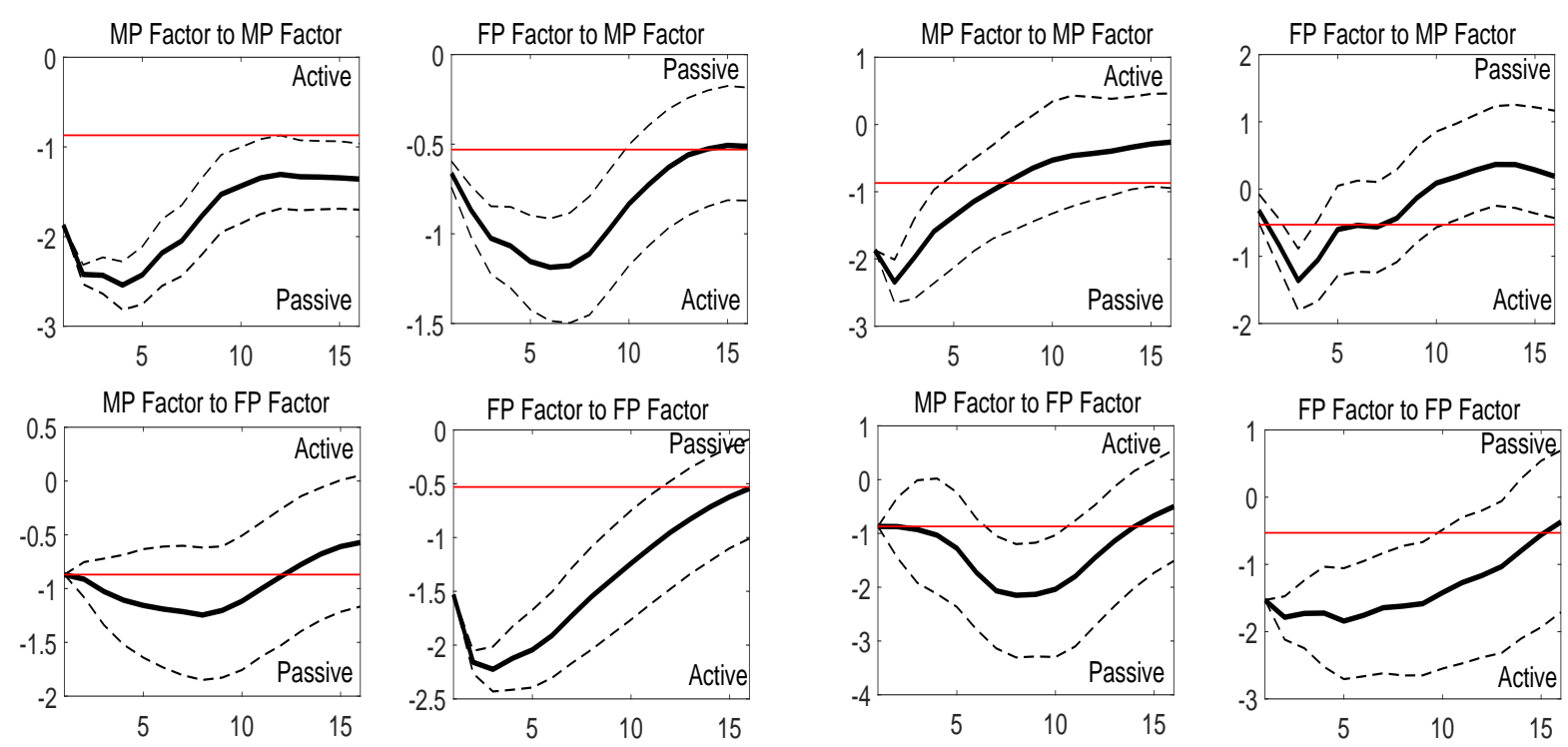

Notes: Figure 17 presents impulse responses to a negative one standard deviation shock to MP and FP regimes for full (left) and subsample (right) period (1949:2-2014:2). Dotted lines represent 90\% confidence intervals. Red lines are estimated thresholds for monetary and fiscal policy rules. 


\section{Appendix D: Adaptive LASSO Method}

Tibshirani (1996) proposes the LASSO method, which adds a penalty for model complexity $\left(L_{1^{-}}\right.$ regularization) to OLS regression, yielding solutions that are sparse in terms of the regression coefficients. To be specific, let $y$ denote either monetary regime factor or fiscal regime factor and $X$ the set of potential candidate variables. ${ }^{38}$ Then the LASSO estimator is given as

$$
\hat{\beta}_{L}(\lambda)=\underset{\beta}{\operatorname{argmin}}(y-X \beta)^{\prime}(y-X \beta)+\lambda \sum_{i=1}^{N}\left|\beta_{i}\right|,
$$

where $\lambda$ is a nonnegative regularization parameter and $N$ the dimension of $X$. It is well known that the solution to LASSO objective function is nonlinear and no closed form solution exists. Among several algorithms proposed for obtaining LASSO solution, we consider the modified least-angle regression (LARS) algorithm suggested in Efron et al. (2004) and Rosset and Zhu (2007) to solve the entire solution path of the LASSO. To ensure that we select a model that gives a balance between the goodness of fit and the complexity of the model, we use the Akaike Information Criterion (AIC). Specifically, we choose the regularization parameter $\lambda$ which minimizes the AIC given by $A I C(\lambda)=\|y-X \beta(\lambda)\|^{2}+2 \sigma_{\epsilon}^{2} d f(\lambda)$, where $d f(\lambda)$ the degree of freedom given by the number of nonzero coefficients and $\sigma_{\epsilon}^{2}$ represents the residual variance of a low-bias model which is equivalent to a ridge regression when its penalty term goes zero. Using the LARS algorithm and AIC, we can obtain the set of the selected variables $X_{L}$ where $L=\left\{i: \beta_{i} \neq 0\right\}$, their coefficients $\hat{\beta}_{L}$ and the associated regularization parameter $\lambda$.

Fan and Li (2001) conjecture the lack of oracle property in the LASSO estimates, and Zou (2006) introduces the adaptive LASSO method and shows that it has the oracle property, which in particular implies that we may treat the regression with the selected regressors as if it were the true regression model. Basically the adaptive LASSO method replaces the $L_{1}$-regularization in the LASSO objective function with a properly chosen weighted $L_{1}$-penalty term, i.e.,

$$
\hat{\beta}_{L}(\delta, \lambda)=\underset{\beta}{\operatorname{argmin}}(y-X \beta)^{\prime}(y-X \beta)+\lambda \sum_{i=1}^{N} \frac{\left|\beta_{i}\right|}{\left|\hat{\beta}_{i}(\delta)\right|},
$$

where $\lambda$ is a nonnegative regularization parameter, $N$ the dimension of $X$, and $\left|\hat{\beta}_{i}(\delta)\right|$ is the adaptive weight given by the ridge regression estimate $\hat{\beta}_{i}$ obtained with a properly chosen ridge regression parameter $\delta{ }^{39}$ The weights are therefore bigger when the true coefficients are large, thereby giving smaller penalties when the associated variables contribute significantly to explaining $y$.

Zou (2006) shows that the adaptive LASSO objective function also can be solved by the same LARS algorithm used for solving the LASSO objective function with only a minor modification.

\footnotetext{
${ }^{38} y$ is the demeaned series and $X$ is the set of standardized series. We transform $X$ properly to ensure stationarity before standardization. Required transformation is done using the code based on Koop and Korobilis (2010) and described in Appendix E.

${ }^{39}$ Due to the possibility of having a high level of collinearity among the large number of predictors considered in our analysis, we use the ridge regression estimate which is more stable than the OLS estimate.
} 
We choose the ridge regression parameter $\delta$ and the regularization parameter $\lambda$, which minimize the AIC. Specifically, we fix a ridge regression parameter $\delta$ at a value ranging from 0 to 4 with 0.001 increment and obtain the entire solution path of the adaptive LASSO for each given $\delta$ using the modified LARS algorithm. We find the combination of $\delta$ and $\lambda$ which minimizes AIC, and select the corresponding variables as the predictors for each of our target variables, monetary and fiscal regime factors. 


\section{Appendix E: Data Description}

All series were downloaded from St. Louis's FRED database and cover from 1959:1 to 2014:2. Some series come from the Global Insights Basic Economics Database. ${ }^{40}$ Some constructed fiscal variables come from NIPA Table 3.2 and debt-to-GDP ratio is from the Federal Reserve Bank of Dallas' database. All series were seasonally adjusted. Some series in the database were observed only on a monthly basis, and quarterly values were computed by averaging the monthly values over the quarter. All variables are transformed to be approximate stationary. The transformation codes are 1: no transformation, 2: first difference, 4: logarithm, 5: first difference of logarithm. An asterisk $(*)$ next to the mnemonic denotes a variable constructed by the authors.

Table 7: Data Description

\begin{tabular}{l|l|c|l}
\hline & Mnemonic & T.Code & Description \\
\hline 1 & CBI & 1 & Change in Private Inventories \\
2 & GDPC96 & 5 & Real Gross Domestic Product, 3 Decimal \\
3 & FINSLC96 & 5 & Real Final Sales of Domestic Product, 3 Decimal \\
4 & CIVA & 1 & Corporate Inventory Valuation Adjustment \\
5 & CP & 5 & Corporate Profits After Tax \\
6 & CNCF & 5 & Corporate Net Cash Flow \\
7 & GDPCTPI & 5 & Gross Domestic Product: Chain-type Price Index \\
8 & FPI & 5 & Fixed Private Investment \\
9 & GSAVE & 5 & Gross Saving \\
10 & PRFI & 5 & Private Residential Fixed Investment \\
11 & CMDEBT & 5 & HH Sector: Liabilites: HH Credit Mkt. Debt Outstanding \\
12 & INDPRO & 5 & Industrial Production Index \\
13 & NAPM & 1 & ISM Manufacturing: PMI Composite Index \\
14 & HCOMPBS & 5 & Business Sector: Compensation Per Hour \\
15 & HOABS & 5 & Business Sector: Hours of All Persons \\
16 & RCPHBS & 5 & Business Sector: Real Compensation Per Hour \\
17 & ULCBS & 5 & Business Sector: Unit Labor Cost \\
18 & COMPNFB & 5 & Nonfarm Business Sector: Compensation Per Hour \\
19 & HOANBS & 5 & Nonfarm Business Sector: Hours of All Persons \\
20 & COMPRNFB & 5 & Nonfarm Business Sector: Real Compensation Per Hour \\
23 & UEMPLT5 & 5 & Civilians Unemployed - Less Than 5 Weeks \\
24 & UEMP5TO14 & 5 & Civilian Unemployed for 5-14 Weeks \\
25 & UEMP15OV & 5 & Civilians Unemployed - 15 Weeks \& Over \\
26 & UEMP15T26 & 5 & Civilians Unemployed for 15-26 Weeks \\
27 & UEMP27OV & 5 & Civilians Unemployed for 27 Weeks and Over \\
28 & NDMANEMP & 5 & All Employees: Nondurable Goods Manufacturing \\
29 & MANEMP & 5 & Employees on Nonfarm Payrolls: Manufacturing \\
30 & SRVPRD & 5 & All Employees: Service-Providing Industries \\
& & &
\end{tabular}

\footnotetext{
${ }^{40}$ Series mnemonic: HHSNTN, PMNO, PMDEL, PMNV, MOCMQ, MSONDQ, DIJA, JSPINDN, JSPNS
} 


\begin{tabular}{|c|c|c|c|}
\hline 31 & USTPU & 5 & All Employees: Trade, Transportation \& Utilities \\
\hline 32 & USWTRADE & 5 & All Employees: Wholesale Trade \\
\hline 33 & USTRADE & 5 & All Employees: Retail Trade \\
\hline 34 & USFIRE & 5 & All Employees: Financial Activities \\
\hline 35 & USEHS & 5 & All Employees: Education \& Health Services \\
\hline 36 & USPBS & 5 & All Employees: Professional \& Business Services \\
\hline 37 & USINFO & 5 & All Employees: Information Services \\
\hline 38 & USSERV & 5 & All Employees: Other Services \\
\hline 39 & USPRIV & 5 & All Employees: Total Private Industries \\
\hline 40 & USGOVT & 5 & All Employees: Government \\
\hline 41 & USLAH & 5 & All Employees: Leisure \& Hospitality \\
\hline 42 & AHECONS & 5 & Average Hourly Earnings: Construction \\
\hline 43 & AWOTMAN & 1 & Average Weekly Hours: Overtime: Manufacturing \\
\hline 44 & AWHMAN & 1 & Average Weekly Hours: Manufacturing \\
\hline 45 & AHEMAN & 5 & Average Hourly Earnings: Manufacturing \\
\hline 46 & AHETPI & 5 & Average Hourly Earnings: Total Private Industries \\
\hline 47 & HOUST & 4 & Housing Starts: Total: New Privately Owned Housing U.S. \\
\hline 48 & HOUSTNE & 4 & Housing Starts in Northeast Census Region \\
\hline 49 & HOUSTMW & 4 & Housing Starts in Midwest Census Region \\
\hline 50 & HOUSTS & 4 & Housing Starts in South Census Region \\
\hline 51 & HOUSTW & 4 & Housing Starts in West Census Region \\
\hline 52 & HOUST1F & 4 & Privately Owned Housing Starts: 1-Unit Structures \\
\hline 53 & PERMIT & 4 & New Private Housing Units Authorized by Building Permit \\
\hline 54 & PCEPI & 5 & PCE: Total (Index 2009=100) \\
\hline 55 & PCEPISERV & 5 & PCE: Services (Index 2009=100) \\
\hline 56 & PCEPISNOND & 5 & PCE: Nondurable Good (Index 2009=100) \\
\hline 57 & PCEPIDUR & 5 & PCE: Durable Good (Index 2009=100) \\
\hline 58 & NONREVSL & 5 & Total Nonrevolving Credit Outstanding, SA, Billions of $\$$ \\
\hline 59 & USGSEC & 5 & U.S. Government Securities at All Commercial Banks \\
\hline 60 & OTHSEC & 5 & Other Securities at All Commercial Banks \\
\hline 61 & TOTALSL & 5 & Total Consumer Credit Outstanding \\
\hline 62 & BUSLOANS & 5 & Commercial and Industrial Loans at All Commercial Banks \\
\hline 63 & CONSUMER & 5 & Consumer (Individual) Loans at All Commercial Banks \\
\hline 64 & LOANS & 5 & Total Loans and Leases at Commercial Banks \\
\hline 65 & LOANINV & 5 & Total Loans and Investments at All Commercial Banks \\
\hline 66 & REALLN & 5 & Real Estate Loans at All Commercial Banks \\
\hline 67 & AMBSL & 5 & Board of Governors Monetary Base, Adjusted \\
\hline 68 & TOTRESNS & 5 & Total Reserves of Depository Institutions \\
\hline 69 & NFORBRES & 1 & Net Free or Borrowed Reserves of Depository Institutions \\
\hline 70 & M1SL & 5 & M1 Money Stock \\
\hline 71 & CURRSL & 5 & Currency Component of M1 \\
\hline 72 & CURRDD & 5 & Currency Component of M1 Plus Demand Deposits \\
\hline 73 & DEMDEPSL & 5 & Demand Deposits at Commercial Banks \\
\hline 74 & TCDSL & 5 & Total Checkable Deposits \\
\hline 75 & TB3MS & 1 & 3-Month Treasury Bill: Secondary Market Rate \\
\hline 76 & TB6MS & 1 & 6-Month Treasury Bill: Secondary Market Rate \\
\hline 77 & GS1 & 1 & 1-Year Treasury Constant Maturity Rate \\
\hline 78 & GS3 & 1 & 3-Year Treasury Constant Maturity Rate \\
\hline
\end{tabular}




\begin{tabular}{|c|c|c|c|}
\hline 79 & GS5 & 1 & 5-Year Treasury Constant Maturity Rate \\
\hline 80 & GS10 & 1 & 10-Year Treasury Constant Maturity Rate \\
\hline 81 & MPRIME & 1 & Bank Prime Loan Rate \\
\hline 82 & AAA & 1 & Moody's Seasoned Aaa Corporate Bond Yield \\
\hline 83 & sTB3MS & 1 & TB3MS - FEDFUNDS \\
\hline 84 & sTB6MS & 1 & TB6MS - FEDFUNDS \\
\hline 85 & sGS1 & 1 & GS1 - FEDFUNDS \\
\hline 86 & sGS3 & 1 & GS3 - FEDFUNDS \\
\hline 87 & sGS5 & 1 & GS5 - FEDFUNDS \\
\hline 88 & sGS10 & 1 & GS10 - FEDFUNDS \\
\hline 89 & sMPRIME & 1 & MPRIME - FEDFUNDS \\
\hline 90 & sAAA & 1 & AAA - FEDFUNDS \\
\hline 91 & sBAA & 1 & BBB - FEDFUNDS \\
\hline 92 & EXSZUS & 5 & Switzerland / U.S. Foreign Exchange Rate \\
\hline 93 & EXJPUS & 5 & Japan / U.S. Foreign Exchange Rate \\
\hline 94 & DJIA & 5 & Dow Jones Stock Avg-30 Ind Stocks \\
\hline 95 & JS\&PINDNS & 5 & S\&P Stock Price Index-400 Industrials \\
\hline 96 & JS\&PNS & 5 & S\&P Stock Price Index-Comp (Common Stocks) \\
\hline 97 & PPIACO & 5 & PPI: All Commodities \\
\hline 98 & PPICRM & 5 & PPI: Crude Materials for Further Processing \\
\hline 99 & PPIFCF & 5 & PPI: Finished Consumer Foods \\
\hline 100 & PPIFCG & 5 & PPI: Finished Consumer Goods \\
\hline 101 & PFCGEF & 5 & PPI: Finished Consumer Goods Excluding Foods \\
\hline 102 & PPIFGS & 5 & PPI: Finished Goods \\
\hline 103 & PPICPE & 5 & PPI: Finished Goods: Capital Equipment \\
\hline 104 & PPIENG & 5 & PPI: Fuels \& Related Products \& Power \\
\hline 105 & PPIIDC & 5 & PPI: Industrial Commodities \\
\hline 106 & PPIITM & 5 & PPI: Intermediate Materials: Supplies \& Components \\
\hline 107 & CPIAUCSL & 5 & CPI For All Urban Consumers: All Items \\
\hline 108 & CPIUFDSL & 5 & CPI for All Urban Consumers: Food \\
\hline 119 & CPIENGSL & 5 & CPI for All Urban Consumers: Energy \\
\hline 110 & CPILEGSL & 5 & CPI for All Urban Consumers: All Items Less Energy \\
\hline 111 & CPIULFSL & 5 & CPI for All Urban Consumers: All Items Less Food \\
\hline 112 & CPILFESL & 5 & CPI for All Urban Consumers: All Items Less Food \& Energy \\
\hline 113 & OILPRICE & 5 & Spot Oil Price: West Texas Intermediate \\
\hline 114 & COMINDX & 5 & CRB BLS Spot Index \\
\hline 115 & $\mathrm{PMNO}$ & 1 & NAPM New Orders Index (Percent) \\
\hline 116 & PMDEL & 1 & NAPM Vendor Deliveries Index (Percent) \\
\hline 117 & PMNV & 1 & NAPM Inventories Index (Percent) \\
\hline 118 & MOCMQ & 5 & New Orders, Consumer Goods \& Materials, 1996 Dollars (BCI) \\
\hline 119 & MSONDQ & 5 & New Orders, Nondefence Capital Goods, 1996 Dollars (BCI) \\
\hline 120 & HHSNTN & 1 & U. of Michigan Index of Consumer Expectation \\
\hline 121 & TGDPR* & 1 & Tax-GDP Ratio \\
\hline 122 & SPGDPR $^{*}$ & 2 & Government Spending-GDP Ratio \\
\hline 123 & DEBGDPR $^{*}$ & 1 & Debt-GDP Ratio \\
\hline 124 & MILGDPR* & 2 & Military Spending-GDP Ratio \\
\hline 125 & INTDET* & 1 & Net Interest Payment-Debt Ratio \\
\hline 126 & OUTGAP* & 1 & Output Gap \\
\hline 127 & NETINT* & 1 & Net Interest Payment-Government Outlays Ratio \\
\hline
\end{tabular}

